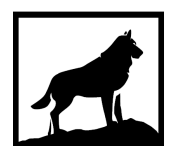

Michigan

Technological

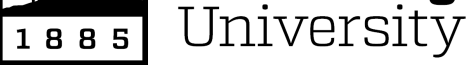

Michigan Technological University

Digital Commons @ Michigan Tech

UNDERSTANDING THE WEATHER- AND SOIL-RELATED VARIABILITY IN AGRICULTURAL WATER FOOTPRINTS: CASE STUDY OF MAIZE AND SOYBEANS GROWN IN THE ST. JOSEPH WATERSHED

Karleigh M. Krieg

Michigan Technological University, kmsundqu@mtu.edu

Copyright 2021 Karleigh M. Krieg

Recommended Citation

Krieg, Karleigh M., "UNDERSTANDING THE WEATHER- AND SOIL-RELATED VARIABILITY IN AGRICULTURAL WATER FOOTPRINTS: CASE STUDY OF MAIZE AND SOYBEANS GROWN IN THE ST. JOSEPH WATERSHED", Open Access Master's Report, Michigan Technological University, 2021. https://doi.org/10.37099/mtu.dc.etdr/1247

Follow this and additional works at: https://digitalcommons.mtu.edu/etdr

Part of the Environmental Engineering Commons 


\title{
UNDERSTANDING THE WEATHER-AND SOIL-RELATED VARIABILITY IN AGRICULTURAL WATER FOOTPRINTS: CASE STUDY OF MAIZE AND SOYBEANS GROWN IN THE ST. JOSEPH WATERSHED
}

By

Karleigh Marie Krieg

\author{
A REPORT \\ Submitted in partial fulfillment of the requirements for the degree of \\ MASTER OF SCIENCE \\ In Environmental Engineering
}

MICHIGAN TECHNOLOGICAL UNIVERSITY

2021

(c) 2021 Karleigh Marie Krieg 
This report has been approved in partial fulfillment of the requirements for the Degree of MASTER OF SCIENCE in Environmental Engineering.

Department of Civil, Environmental, and Geospatial Engineering

$\begin{aligned} \text { Report Advisor: } & \text { Dr. David Watkins } \\ \text { Committee Member: } & \text { Dr. Robert Handler } \\ \text { Committee Member: } & \text { Dr. Xinyu Ye } \\ \text { Department Chair: } & \text { Dr. Audra Morse }\end{aligned}$




\section{Contents}

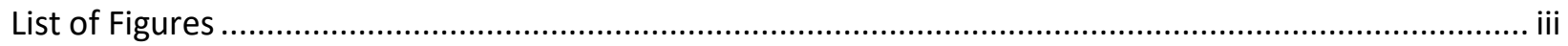

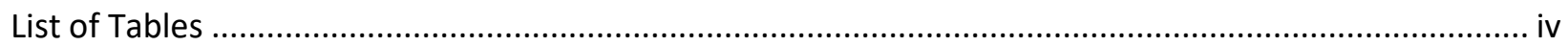

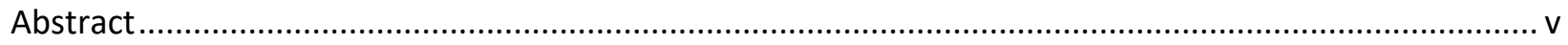

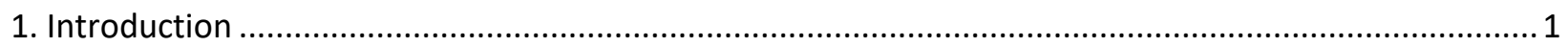

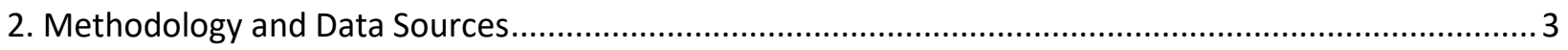

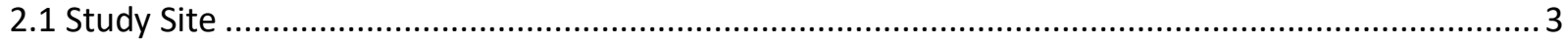

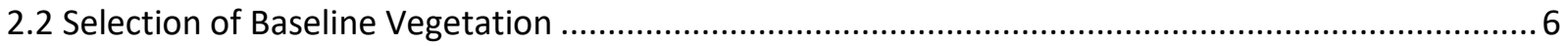

2.3 Hydrologic and Water Quality System (HAWQS) Model ............................................................ 6

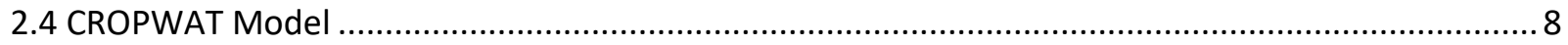

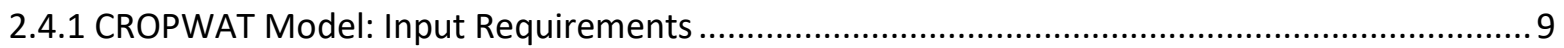

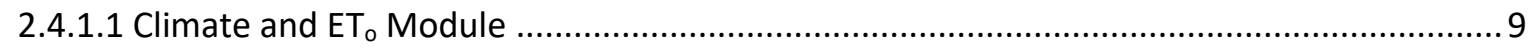

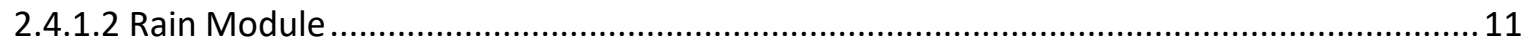

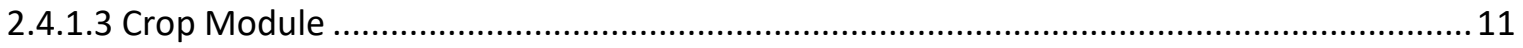

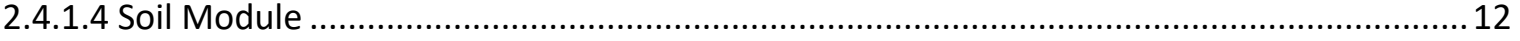

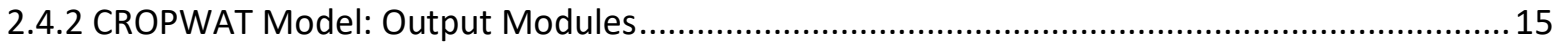

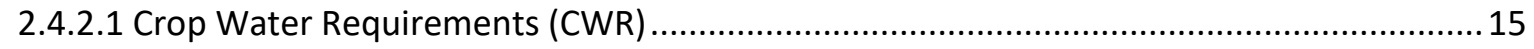

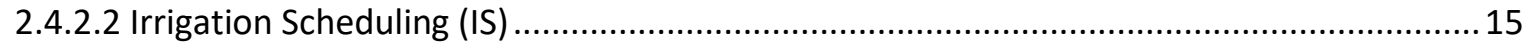

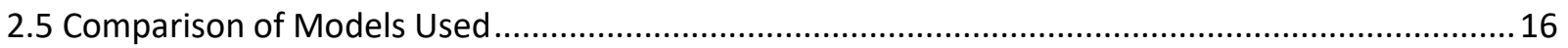

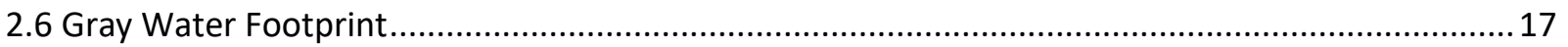

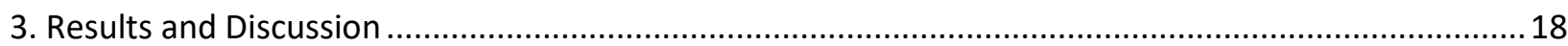

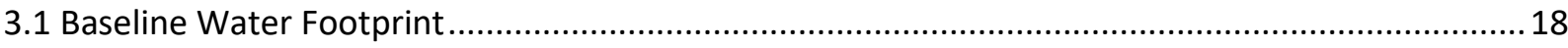

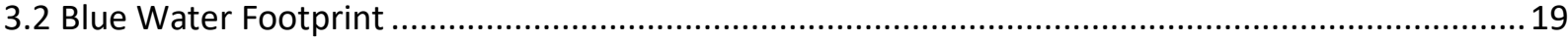

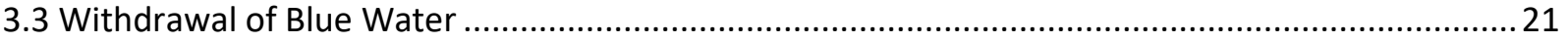

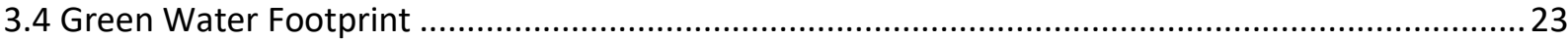

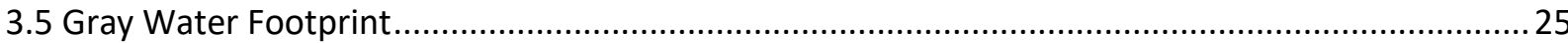

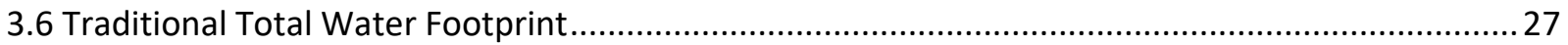

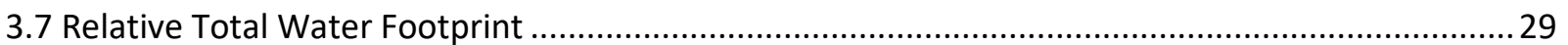

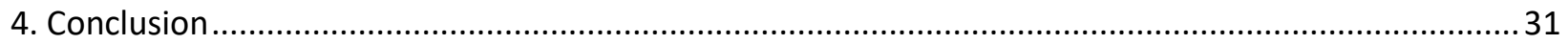

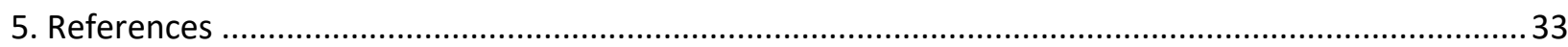

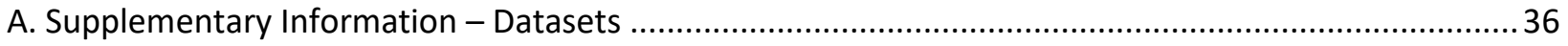

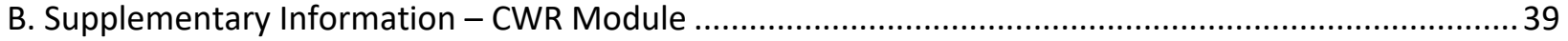




\section{List of Figures}

Figure 1. Topographic map of the southwestern portion of Michigan and northern Indiana, with the boundary of the St. Joseph watershed mapped. Inlet shows the 15 Midwestern counties that are a part of the St. Joseph watershed; Michigan counties outlined in red and Indiana counties outlined in blue (map created by author in ESRI ArcGIS Pro).

Figure 2. Land use distribution for the St. Joseph Watershed based on HRUs. Thresholds were applied to eliminate HRUs that had areas less than $0.01 \mathrm{~km}^{2}$

Figure 3. HAWQS output of the evapotranspiration of deciduous trees grown in the St. Joseph watershed, expressed in units of $\mathrm{mm}$ per day. The ET rates were simulated using daily time-steps then averaged for each month....

Figure 4. Hydrologic soil groups in the St. Joseph watershed at spatial resolution of 30-meters (NRCS, 2020A).

Figure 5. Distribution of soil drainage classes across the watershed at spatial resolution of 30-meters

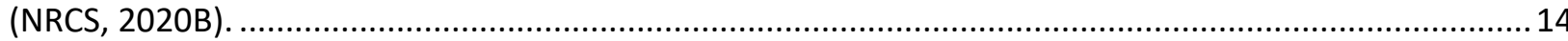

Figure 6. Comparison of source for baseline ET rates baseline water footprints..................................... 18 Figure 7. Consumptive blue water footprint calculated from the irrigation at critical depletion simulated with maize (A) and soybeans (B) for the 2016 growing season Figure 8. Withdrawal blue water footprint calculated from simulating irrigation at critical depletion with maize $(A)$ and soybeans $(B)$.

Figure 9. Green water footprints using the two irrigation scheduling options for maize (A) and soybeans (B).

Figure 10. Gray water footprint for maize (blue, primary y-axis) and soybeans (orange, secondary y-axis) grown by county.

Figure 11. Traditional total water footprint for maize (primary $y$-axis) and soybeans (secondary y-axis) in St. Joseph watershed

Figure 12. Contribution of each component of the total water footprint for maize (A) and soybeans (B).

Figure 13. Relative water footprint as calculated using Equation 6 for maize (primary $y$-axis) and soybeans (secondary y-axis) with the baseline ET rates from HAWQS model.

Figure 14. Relative water footprint as calculated using Equation 6 for maize (primary y-axis) and soybeans (secondary y-axis) with the baseline ET rates from the Hamilton et al. (2018) field study........30 Figure 15. Relative total water footprint with gray water footprint component excluded for maize (primary $y$-axis) and soybeans (secondary y-axis) using both methods that quantify the baseline ET rates, represented as an average of all simulated soils. 


\section{List of Tables}

Table 1.Total water footprint $\left(\mathrm{m}^{3}\right.$ year $\left.{ }^{-1}\right)$ for the ten most water-intensive non-livestock products produced globally and produced in the United States (Hoekstra and Mekonnen, 2020).

Table 2. National Land Cover Dataset (NLCD) applied to the St. Joseph watershed, with similar classes combined, showing the percent that each land cover class is present from 2001-2016 (MRLC, 2016)..... 4 Table 3. Crop Data Layers for 2016, expressed as percentages that each crop comprises of the cultivated cropland (NASS, 2016).

Table 4. 2017 Census of Agriculture Output for Counties in St. Joseph watershed (USDA, 2019). These values come from county-level datasets for selected field crops harvested, which would be Table 24 in the census documentation.

Table 5. Weather Station data for each county in the St. Joseph watershed, climate data and station consulted for the 2016 observation year.

Table 6. Wind speed listed as the average for the month in 2016 and used as the monthly wind speed experienced across the entire watershed (NOAA, n.d., B).

Table 7. Required parameters for daylight hour calculations. ............................................................... 10

Table 8. Precipitation data for 2016 growing season of each county. ................................................... 11

Table 9. Crop characteristics for maize and soybeans (Allen, 1998) as well as the usual planting \& harvest

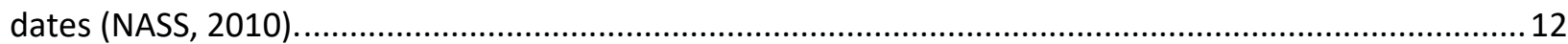

Table 10. Percentage of each hydrologic soil group that can be found in the watershed.......................12

Table 11. Area of the St. Joseph watershed comprised of various soil drainage classes, with the simplified classes being the summation of similar classes' surface area...........................................................13

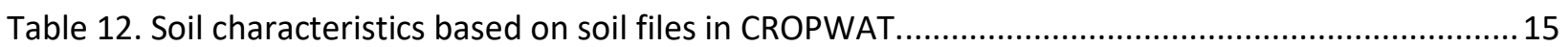

Table 13. Conversion of HAWQS model output $\left(\mathrm{mm} \mathrm{day}^{-1}\right.$ ) to crop water use terms (units of $\mathrm{m}^{3}$ hectare $\mathrm{C}^{-1}$ )

Table 14. Acres planted and harvested volume of agricultural crops in the St. Joseph watershed, with estimated application rate of phosphorus and calculated gray water footprint. 


\section{Abstract}

Introduced in 2002, the water footprint is a valuable tool for understanding the consumption of freshwater resources. The traditional approach to quantifying the water footprint is to sum the green, blue, and gray water footprint components. The green water footprint is the volume of water that comes from precipitation, is stored in the soil, and used by vegetation. The blue water footprint is the volume of surface or ground water that is withdrawn and applied to cultivated lands via irrigation. These components are based on the evapotranspiration of green and blue water resources, respectively. The gray water footprint is the volume of water that is needed to dilute the resultant pollutants to ensure compliance with water quality standards in natural water bodies.

Though applicable to many products and at a range of scales, the water footprint methodology is most commonly applied to agricultural products. This is because of the large volumes of water that products from this industry require. For example, in the U.S., maize and soybeans require $190 \times 10^{9}$ and $120 \times 10^{9}$ $\mathrm{m}^{3}$ in total water per year. Due to the large demands of water, applying the water footprint to an area with intensive agriculture is beneficial to effective resource management, even in areas with abundant water resources such as the Great Lakes Basin, which contains $21 \%$ of the world's freshwater resources. Thus, the St. Joseph watershed, which is located in this area, will be investigated for how maize and soybean produced affect the freshwater resources.

Because of the lack of insight gained from the traditional water footprint regarding the effects that water depletion has on local landscapes, a new approach is proposed, called the relative water footprint. Using this approach, it is shown that relative to a natural landscape of woody vegetation and deciduous trees, the agricultural water demands of the St. Joseph watershed are greatly reduced, at least in terms of the green water footprint. However, the blue and gray water footprints for maize and soybeans may still be significant and highly variable, with blue water footprints dependent on rainfall patterns, soil types, and irrigation scheduling, and gray water footprints dependent on fertilizer application rates. 


\section{Introduction}

Introduced in 2002, the water footprint (Hoekstra, 2003) is a valuable tool for understanding the consumption of freshwater resources. Specifically, the water footprint is a volumetric measurement of the water consumption and water pollution associated with a supply chain. The traditional approach to quantifying the water footprint is as follows:

$$
\begin{gathered}
W F_{\text {total }}=W F_{\text {green }}+W F_{\text {blue }}+W F_{\text {gray }} \\
W F_{\text {green }}=\frac{\sum E T_{\text {green }}}{Y} \\
W F_{\text {blue }}=\frac{\sum E T_{\text {blue }}}{Y} \\
W F_{\text {gray }}=\frac{\alpha * A R}{Y *\left(c_{\text {max }}-c_{\text {nat }}\right)}
\end{gathered}
$$

The total water footprint, $W F_{\text {total }}$, is the sum of the green, blue and gray water footprints (Equation 1 ). The green water footprint, $W F_{\text {green }}$, is the volume of rainwater that is consumed along the supply chain (Equation 2). In the context of agricultural products (non-livestock), it is the volume of green water -- total rainfall that evaporates from the field during the growing season -- that comes from rain, is stored in the soil, and finally used by the crop. The blue water footprint, $W F_{\text {blue }}$, is the volume of blue water resources - such as surface water and ground water -- consumed along the supply chain (Equation 3 ) via irrigation techniques. This consumptive water use refers to the evapotranspiration (ET) of blue water resources, the incorporation of blue water resources into a product, or to the water resources that do not return to the same area from where it was originally withdrawn. The green and blue water footprints are based on the ET of green and blue water resources, respectively. Finally, the gray water footprint, $W F_{\text {gray }}$, is the volume of water needed to assimilate the concentration of pollutants along the supply chain to follow local water quality standards and not exceed the natural background concentrations (Equation 4). Rather than representing compliance, or non-compliance, with regulated standards, the gray water footprint shows that a water body's capacity to adapt to pollution has been expended. In an agricultural environment, pollutants generally consist of nutrient loadings in fertilizers (nitrogen and phosphorus, predominately), as well as chemicals used to prevent damage to crops from biological factors (such as insecticides and pesticides). The rate at which the contaminant is applied, $A R$, the leaching run-off fraction, $\alpha$, the maximum acceptable concentration $c_{\text {max }}$, and the natural concentration, $c_{n a t}$ are required to quantify this water footprint. In each of these components, the variable, $Y$, is present, which is the yield for the crop of interest. The Food and Agriculture Organization's (FAO) CROPWAT will function as the primary calculator of the green and blue ET rates. CROPWAT is an appropriate software to use due to it employing empirical formulas for estimating ET based on input data on climate, soil and crop characteristics (Allen et al., 1998).

The water footprint is a versatile concept. Several studies have been done on the water footprint of a product, a country, or a corporation, to name just a few of its applications. One industry in particular is often analyzed - agriculture - since products from this sector are recognized as having large water footprints on the global stage (Table 1; Hoekstra and Mekonnen, 2020). This is evident from the majority of seminal articles dedicated to investigating the water footprints of products from this sector. Chapagain and Hoekstra (2003) published a research report that detailed the flow of water between nations that is embedded in the production and trade of livestock and related products, as well as a publication on the 
relationship between water use and the consumption of coffee and tea (Chapagain and Hoekstra, 2007). Additional studies include an investigation into the total water footprint associated with consuming and producing rice (Chapagain and Hoekstra, 2010); a case study on the water footprint of food waste associated with unsalable products in the Australian mango industry (Ridoutt et al., 2010); and finally, a research report that provided a methodology and improvements to such a methodology for investigating the total water footprint of paper products (Van Oel and Hoekstra, 2010). Staple food crops, such as wheat, maize, and soybeans, are ubiquitous across the globe. The major exporting countries of these crops are the U.S., Argentina, and Canada. The U.S. alone exports $56 \%$ of the maize, $50 \%$ of the soybeans, and $24 \%$ of the wheat. For each of these crops, the U.S. has the largest green and blue water footprints (Aldaya et al., 2010), suggesting that analyses with increased spatial resolution will be useful to better understand these water footprints. Thus, this study will look at the impacts of maize and soybeans due to the large volume of these crops grown and large water footprints they have at the national level (Table 1).

Table 1.Total water footprint $\left(\mathrm{m}^{3}\right.$ year-1) for the ten most water-intensive non-livestock products produced globally and produced in the United States (Hoekstra and Mekonnen, 2020).

\begin{tabular}{|c|c|c|c|}
\hline $\begin{array}{c}\text { Globally Produced } \\
\text { Product }\end{array}$ & $\begin{array}{c}\text { Total Water Footprint } \\
\left(\mathbf{m}^{\mathbf{3}} \mathbf{y e a r}^{-\mathbf{1}}\right)\end{array}$ & $\begin{array}{c}\text { Nationally Produced } \\
\text { Product (U.S.) }\end{array}$ & $\begin{array}{c}\text { Total Water Footprint } \\
\left(\mathbf{m}^{\mathbf{3}} \mathbf{y e a r}^{-\mathbf{1}}\right)\end{array}$ \\
\hline Wheat & $1100 \times 10^{9}$ & All Fodder Crops & $220 \times 10^{9}$ \\
\hline Rice & $990 \times 10^{9}$ & Maize & $190 \times 10^{9}$ \\
\hline Maize & $760 \times 10^{9}$ & Soybeans & $120 \times 10^{9}$ \\
\hline Sugar Cane & $270 \times 10^{9}$ & Wheat & $120 \times 10^{9}$ \\
\hline Cotton & $230 \times 10^{9}$ & Sorghum & $16 \times 10^{9}$ \\
\hline Barley & $200 \times 10^{9}$ & Rice & $13 \times 10^{9}$ \\
\hline Sorghum & $180 \times 10^{9}$ & Barley & $8.1 \times 10^{9}$ \\
\hline Coconuts & $140 \times 10^{9}$ & Potatoes & $8 \times 10^{9}$ \\
\hline Oil Palm Fruit & $140 \times 10^{9}$ & Sugar Cane & $6.2 \times 10^{9}$ \\
\hline Millets & $130 \times 10^{9}$ & Sugar Beet & $3.3 \times 10^{9}$ \\
\hline
\end{tabular}

Despite its usefulness, a major challenge of the water footprint method regards the guidelines that should be followed when data is limited. Though local data is preferable, many times it becomes too laborious to collect spatially explicit data. Thus, users often rely on rough estimations, nearby locations, or national averages to make water footprint analyses more streamlined. For example, in Ridoutt et al. (2010), the authors found that household-level consumption of mangoes was not known, and thus regional packing stations were consulted. In Chapagain and Hoekstra (2010), which investigated the total water footprint of rice globally, the national-level footprints were calculated using international trade and production of the rice crop. It is here that the authors note that given the different resolutions of the data consulted, errors within the data can greatly affect the results. Thus, it can be difficult to find practical examples of assessments conducted with limited data. Given these data availability issues, this report attempts to demonstrate what sources to consult and equations to employ in instances of limited data that are relevant to the area of interest.

Another limitation of the water footprint method is that it does not consider water availability and the effects of water consumption on alternative, natural landscapes, such as deciduous forests, grasslands, and wetlands. This suggests that the water footprint equation should be modified to account for this (Heidari et al., 2019; Heidari et al., 2020). To do so, this report proposes the use of a baseline water footprint of natural vegetation $W F_{b}$, to capture the impact that water-intensive agricultural products have on land that may be otherwise dominated by native plant species. This revised method provides the 
context of alternative landscapes and resource availability in the following equation, referred to as the relative water footprint, $W F_{\text {total,relative }}$ (Equation 5 ). In this equation, the variable $W F_{b}$ represents water footprint of some natural vegetation. This is used to understand the impact that adjustments to the current land uses might have on the total water budget. This variable is assumed to rely on only green water resources. This means that it is calculated similarly to the green water ET rates, and thereby green water footprint. The Environmental Protection Agency's (EPA) Hydrologic and Water Quality System (HAWQS), models the effects of management practices on the water quantity and water quality at the watershed-level (HAWQS, 2019). For the purpose of this report, this interactive online tool will be used to check the results of CROPWAT and to provide baseline ET values.

$$
\begin{gathered}
W F_{\text {total,relative }}=W F_{\text {blue }}+W F_{\text {green }}+W F_{\text {gray }}-W F_{b} \\
W F_{\text {total,relative }}=\frac{\sum E T_{\text {blue }}}{Y}+\frac{\sum E T_{\text {green }}}{Y}+\frac{\alpha * A R}{Y *\left(c_{\text {max }}-c_{\text {nat }}\right)}-\frac{\sum E T_{\text {green }, b}}{Y}
\end{gathered}
$$

A preliminary investigation into possible datasets used in this study found that 2016 provided a complete set of information regarding climate, land use and volumes of crops harvested. Given the large consumption of freshwater resources that agricultural activity requires, the relationship between agriculture and the freshwater resources needs to be analyzed at various spatial resolutions. Since the Great Lakes Basin is home to approximately $21 \%$ of the freshwater resources (EPA, 2017), analyzing watersheds in this area is beneficial to understanding the local water budget's sensitivity to this water intensive industry. Therefore, this report will focus on the watershed-level within the Great Lakes Basin to provide a methodology for areas that may span more than one political border (such as multiple states, provinces, or counties) as a means to guide policy decisions and establish targets for sustainable water resource management in this location.

\section{Methodology and Data Sources}

\subsection{Study Site}

The St. Joseph watershed spans a total of 15 counties -8 in southwestern Michigan and 7 in northern Indiana. Figure 1 shows the location of the St. Joseph watershed, with county boundaries outlined in red for Michigan and in blue for Indiana. The St. Joseph watershed is selected for analysis for two reasons. First, there has been difficulty in coordinating water resource management in this basin, as noted in an ambitious, yet failed St. Joseph watershed conservation effort (The Friends of the St. Joseph River Association, 2009). Therefore, this study provides additional information for local policy decisions to be made for each of the county-level stakeholders to incorporate sustainable water management practices in the St. Joseph watershed. Secondly, like many watersheds in the Midwest, the St. Joseph watershed drains a rural landscape that is dominated by agricultural activity. An analysis of the land cover using the National Land Cover Datasets (NLCD; MLRC, 2016) shows that this watershed has had an average of $53 \%$ of the land dedicated to crops, with other land uses comprising less than $16 \%$ per category (Table 2 ). Using the USDA's Crop Data Layers (CDL; NASS, 2016), of this cropland, about $23 \%$ of the cultivated land is for growing maize and about $16 \%$ is dedicated to soybean cultivation (Table 3 ). The results regarding maize and soybeans are consistent with what is observed elsewhere in the Midwest: maize is the priority crop, with soybean cultivation increasing in intensity over the last few decades. This motivates the study of water footprints of agricultural lands in this watershed. As shown in equations 2 through 4 , the yield of the annual crops is required to calculate the water footprint. The USDA Census of Agriculture publishes a 
census every 5 years that details such agricultural activity for the U.S. and Puerto Rico. However, yield data is not available for 2016, but can be estimated from the data published in the 2017 census (USDA, 2019). From Table 4, the average yield of maize in 2017 is 162.6 bushels per acre ,and the average yield of soybeans in the same year is 46.9 bushels per acre in the St. Joseph watershed.

Table 2. National Land Cover Dataset (NLCD) applied to the St. Joseph watershed, with similar classes combined, showing the percent that each land cover class is present from 2001-2016 (MRLC, 2016).

\begin{tabular}{|c|c|c|c|c|c|}
\hline NLCD Class & Included Classes & \%, 2001 & \%, 2006 & \%, 2011 & \%, 2016 \\
\hline Developed Land & Low, Middle, High & 12.66 & 12.85 & 12.96 & 13.05 \\
\hline Cropland & - & 52.94 & 53.02 & 53.08 & 53.00 \\
\hline Forest & Deciduous, Evergreen, Mixed & 10.87 & 10.83 & 10.81 & 10.77 \\
\hline Wetlands & Woody wetlands, Emergent Herbaceous & 15.65 & 15.67 & 15.67 & 15.73 \\
\hline Grasses & Hay/pasture, herbaceous, shrub/scrub & 5.44 & 5.15 & 4.96 & 4.99 \\
\hline
\end{tabular}

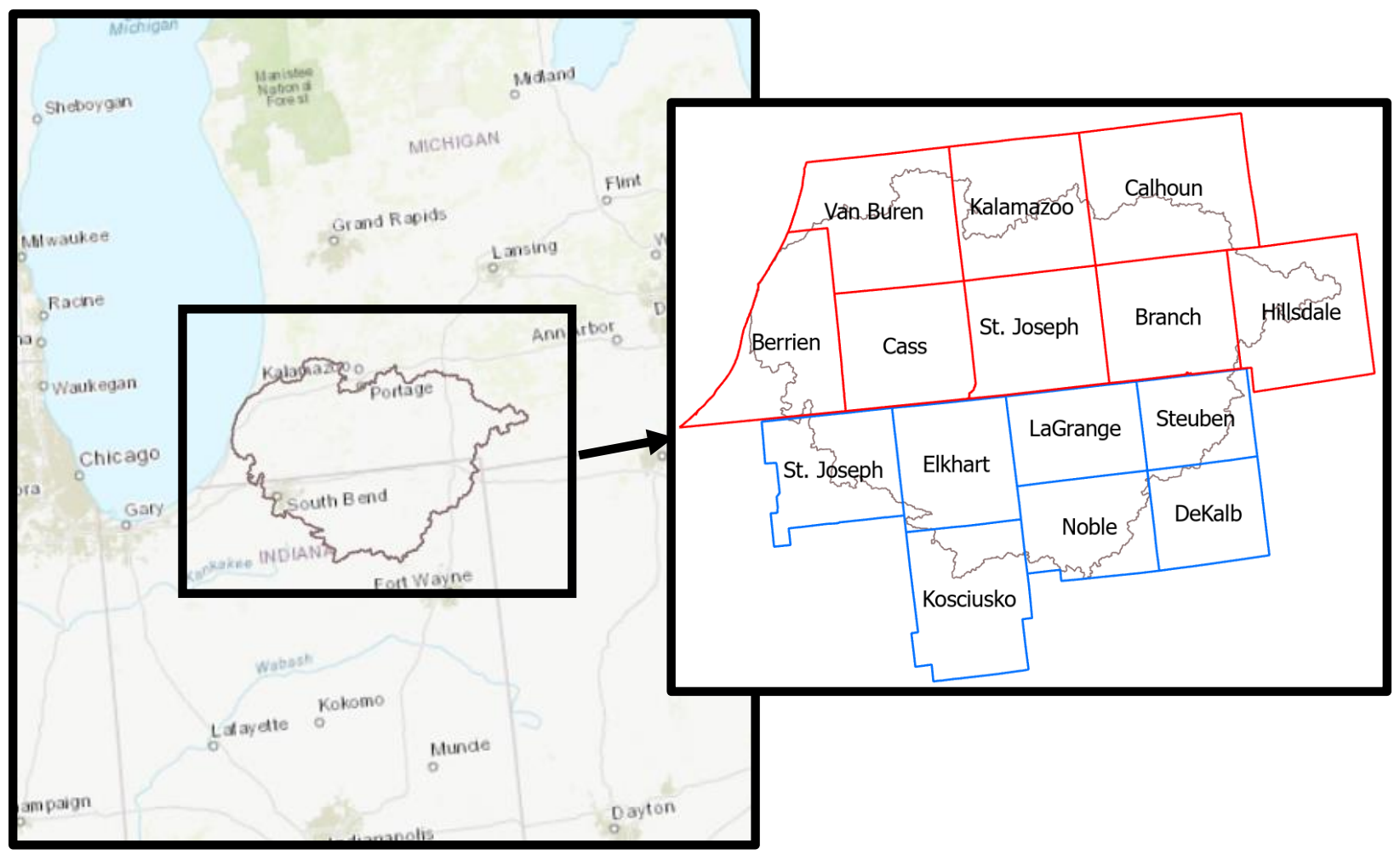

Figure 1. Topographic map of the southwestern portion of Michigan and northern Indiana, with the boundary of the St. Joseph watershed mapped. Inlet shows the 15 Midwestern counties that are a part of the St. Joseph watershed; Michigan counties outlined in red and Indiana counties outlined in blue (map created by author in ESRI ArCGIS Pro). 
Table 3. Crop Data Layers for 2016, expressed as percentages that each crop comprises of the cultivated cropland (NASS, 2016).

\begin{tabular}{|c|c|c|c|}
\hline Crop Type & Layer & Latin Name & \% Of Cropland \\
\hline \multirow{3}{*}{ Annual } & Maize & Zea mays & 23.32 \\
\cline { 2 - 4 } & Soybeans & Glysine max & 15.77 \\
\hline \multirow{4}{*}{ Perennial } & Deciduous Forest & Acer, Quercus & 15.27 \\
\cline { 2 - 4 } & Evergreen Forest & Pinus & 0.11 \\
\cline { 2 - 4 } & Mixed Forest & - & 0.02 \\
\cline { 2 - 4 } & Grass & Festuca arundinacea & 6.47 \\
\hline- & All Other Crops & - & 39.04 \\
\hline
\end{tabular}

Table 4. 2017 Census of Agriculture Output for Counties in St. Joseph watershed (USDA, 2019). These values come from countylevel datasets for selected field crops harvested, which would be Table 24 in the census documentation.

\begin{tabular}{|c|c|c|c|c|c|c|c|}
\hline State & County & $\begin{array}{l}\text { Harvested } \\
\text { Volume, } \\
\text { Maize } \\
\text { (bushels) }\end{array}$ & $\begin{array}{l}\text { Harvested } \\
\text { Area, Maize } \\
\text { (acres) }\end{array}$ & $\begin{array}{c}\text { Yield } \\
\text { (bushels } \\
\text { acre }^{-1} \text { ) }\end{array}$ & $\begin{array}{c}\text { Harvested } \\
\text { Volume, Soybeans } \\
\text { (bushels) }\end{array}$ & $\begin{array}{l}\text { Harvested Area, } \\
\text { Soybeans } \\
\text { (acres) }\end{array}$ & $\begin{array}{c}\text { Yield } \\
\text { (bushels } \\
\text { acre }^{-1} \text { ) }\end{array}$ \\
\hline \multirow{8}{*}{ Michigan } & Berrien & $7,476,440$ & 44,928 & 166.4 & $1,887,041$ & 43,163 & 43.7 \\
\hline & Branch & $14,518,654$ & 92,925 & 156.2 & $3,523,111$ & 81,501 & 43.2 \\
\hline & Calhoun & $9,488,519$ & 69,426 & 136.7 & $2,814,313$ & 73,670 & 38.2 \\
\hline & Cass & $11,935,071$ & 76,640 & 155.7 & $2,742,155$ & 59,407 & 46.2 \\
\hline & Hillsdale & $10,558,633$ & 67,520 & 156.4 & $3,803,596$ & 91,124 & 41.7 \\
\hline & Kalamazoo & $7,605,497$ & 50,140 & 151.7 & $1,752,011$ & 36,566 & 47.9 \\
\hline & St. Joseph & $14,049,421$ & 100,831 & 139.3 & $2,994,733$ & 63,509 & 47.2 \\
\hline & Van Buren & $6,771,823$ & 40,307 & 168.0 & $1,346,118$ & 28,063 & 48.0 \\
\hline \multirow{7}{*}{ Indiana } & DeKalb & $6,783,926$ & 40,291 & 168.4 & $3,501,478$ & 73,525 & 47.6 \\
\hline & Elkhart & $9,738,769$ & 54,209 & 179.7 & $2,407,805$ & 45,614 & 52.8 \\
\hline & Kosciusko & $18,285,030$ & 101,074 & 180.9 & $4,997,538$ & 95,318 & 52.4 \\
\hline & LaGrange & $7,790,199$ & 51,187 & 152.2 & $1,873,754$ & 38,396 & 48.8 \\
\hline & Noble & $12,586,487$ & 69,560 & 180.9 & $3,883,651$ & 77,099 & 50.4 \\
\hline & St. Joseph & $12,258,818$ & 65,435 & 187.3 & $2,708,898$ & 53,398 & 50.7 \\
\hline & Steuben & $6,419,785$ & 40,317 & 159.2 & $1,797,114$ & 40,302 & 44.6 \\
\hline \multicolumn{2}{|c|}{ AVERAGE } & $10,417,805$ & 64,319 & 162.6 & $2,802,221$ & 60,044 & 46.9 \\
\hline
\end{tabular}




\subsection{Selection of Baseline Vegetation}

The CDLs are categorized by crop type: annual (plants grown for a specific period such as traditional cultivated vegetation) versus perennial (plants that are consecutively present year-round such as vegetation that is naturally present in an ecosystem) crops. From Table 3, there are four natural landscapes that can be used as the baseline vegetation for this watershed's investigation. However, since deciduous trees are found in about $15 \%$ of the watershed, and thereby are the dominant perennial vegetation, they will be used as the baseline vegetation.

Estimation of baseline ET rates needs to consider background parameters that mirror those of the site investigated in this study: temperate-humid climates; area dominated by cropland and natural environments with little developed land cover; and the majority of rainfall occurring during the months of May to September. A recent publication (Hamilton et al., 2018) provides baseline ET values for woody vegetation, $E T_{b}=532 \mathrm{~mm}_{\text {year }}{ }^{-1}$, in the Augusta Creek watershed, which is directly north of the St. Joseph watershed. In this study, the "mean growing season ET rate" is considered to represent the ET observed during the growing season of the crop. Since these values are representative of the total ET rate over the growing season, they will be used as the baseline ET rates for the relative water footprint equation.

\subsection{Hydrologic and Water Quality System (HAWQS) Model}

HAWQS is a web-based modeling tool, based on the USDA's Soil and Water Assessment Tool (SWAT), that is designed to simulate the effects of management practices on water quantities (e.g., evapotranspiration, infiltration, streamflow) and water quality at the watershed level (HAWQS, 2019). This interactive online tool can be used to understand the impact that agriculture, natural landscapes, and climate change have on internationally recognized water-related issues, including sediment and nutrient loading, presence of pathogens, organic and synthetic pesticide pollution, and increased water temperatures.

HAWQS simulates user-created scenarios using hydrologic response units (HRUs). These are defined as portions of a watershed that possess homogenous landscapes, management practices, or soil characteristics. Using this approach, accuracy is increased in the analysis since predictions are made based on the total inputs (or loadings) to each of the HRUs in the watershed, and detailed outputs indicate how the various land uses categories and soil types will respond to the loadings. The number of HRUs can be adjusted by specifying a minimum area requirement or by setting a target number of HRUs. For the St. Joseph watershed, a total of $763 \mathrm{HRUs}$ were simulated, where HRUs that had an area less than $0.01 \mathrm{~km}^{2}$ were eliminated, resulting in the land use distribution shown in Figure 2. 


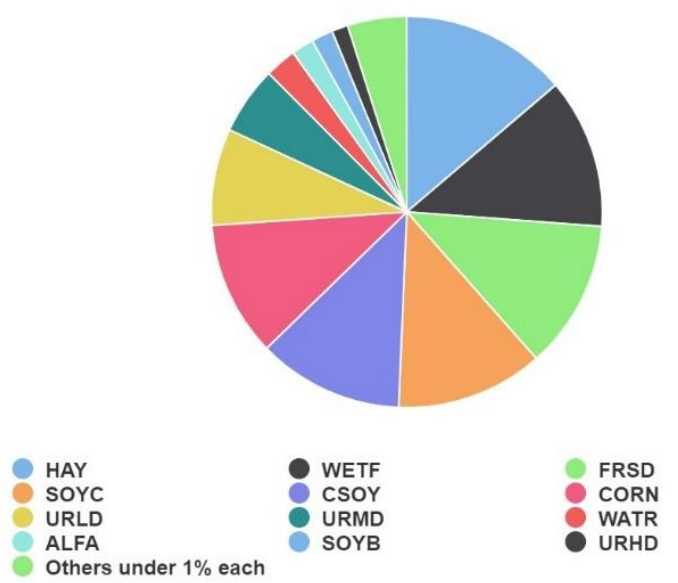

Figure 2. Land use distribution for the St. Joseph Watershed based on HRUs. Thresholds were applied to eliminate HRUs that had areas less than $0.01 \mathrm{~km}^{2}$

In HAWQS, management scenarios need to be defined, which show user-specified input criteria the model needs to consider. Some of the input variables that can be manipulated are the fertilizer inputs, point source pollution, climate change sensitivities, and conservation practices. This study does not consider climate change sensitivities so weather data was sourced from historical weather observations ("NCDC NWS/NOAA" selection from the drop-down menu). The simulation period represents the beginning and end dates through which the model should run. "Set-up/warm-up years" refer to the number of years that are used to establish initial conditions for the simulation period. At least one year of warm-up is required, with 2-5 years being the recommended warm-up duration. To ensure that the model is wellcalibrated, seven warm-up years were selected, and the simulation period was set as January $1^{\text {st }}, 2009$ to December $31^{\text {st }}, 2016$. Another option to customize is the output print setting. HAWQS results can be output at daily and monthly time-steps. Since monthly data prohibits the output of some statistics, the daily time-step was chosen since it allows for a more detailed simulation and more output data to be accessed. However, results are presented herein as averages or totals for the month. Finally, the latest version of SWAT - SWAT 2012 rev. 681 - was chosen. General watershed inputs, subbasin inputs, conservation practice inputs, and other customizable parameters were not modified for this study.

Despite multiple categories of information that can be extracted from the user-created scenarios, the ET rates, in units of $\mathrm{mm} /$ day, were most valuable to this study. With the consideration of different land uses at the HRU scale, HAWQS can provide another source of the baseline ET for natural vegetation. For the analysis year, the HAWQS model approximates the average ET rates of deciduous trees (HRU = FRSD) as $1.20 \mathrm{~mm} \mathrm{day}^{-1}$ (Figure 3). However, the growing season is considered to be more representative of the water use patterns in agricultural systems. For maize and soybeans, the growing season occurs from midMay to mid-October (Table 9; NASS, 2010). Thus, assuming the same growing season for deciduous trees, the growing season ET rates are estimated to be $1.94 \mathrm{~mm} \mathrm{day}^{-1}$.

The Hamilton et al. (2018) study observed that the Augusta Creek watershed experienced ET rates of about $1.46 \mathrm{~mm} \mathrm{day}{ }^{-1}$ for woody vegetation during the growing season. However, as noted above, deciduous trees experience ET at a rate of $1.94 \mathrm{~mm}$ day ${ }^{-1}$. The reason for the difference could be that the Hamilton et al. (2018) study considered two more plant species in the calculation - deciduous forests along 
with shrublands and poplar trees - while this study only considered one type of natural vegetation to simulate in HAWQS. In addition, the Augusta Creek ET rates are representative of the entire analysis year, rather than considering the daily ET rates as in the HAWQS model. Furthermore, the authors of the Augusta Creek study note that the growing season ET rates are about $70 \%$ of the annual rates, while the HAWQS model shows that approximately $80 \%$ of the annual ET occurs during the growing season. Regardless of these slight differences, the values for baseline ET rates are considered to be consistent, and both will be used to calculate the baseline ET rates for the relative water footprint calculation.

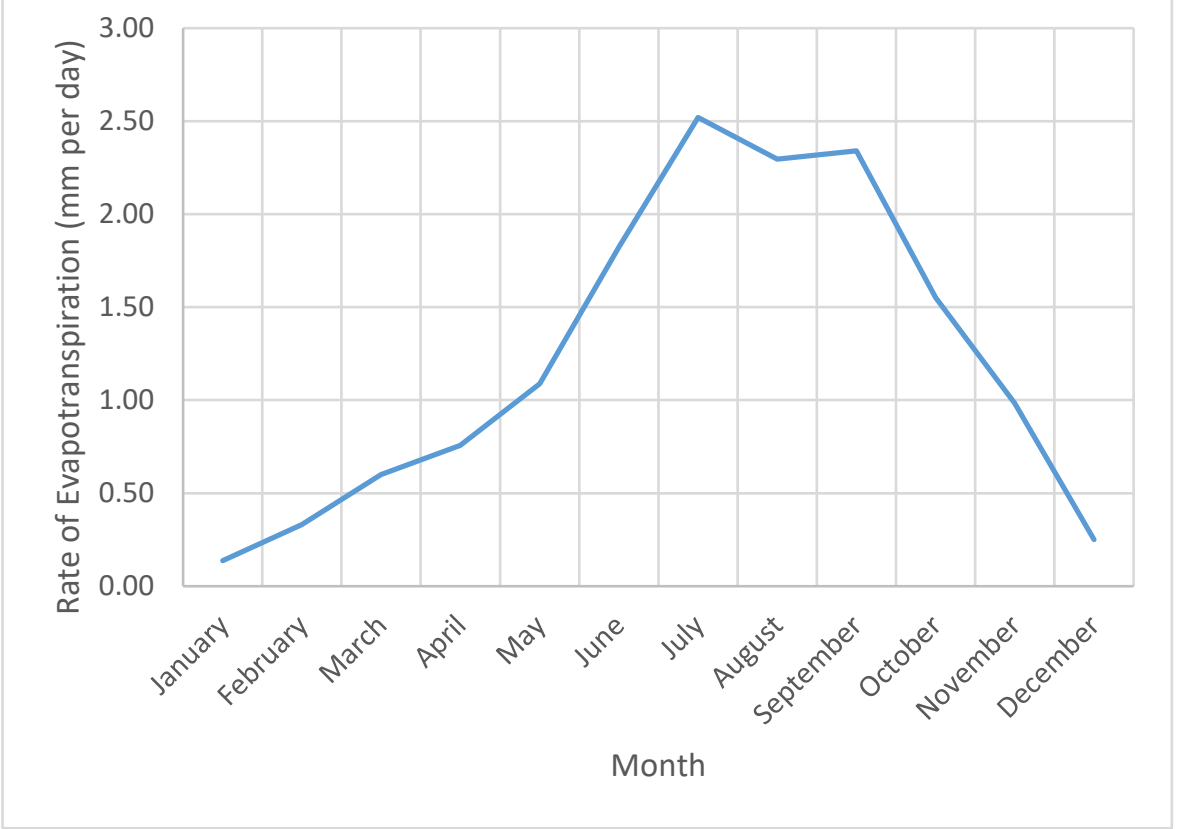

Figure 3. HAWQS output of the evapotranspiration of deciduous trees grown in the St. Joseph watershed, expressed in units of $\mathrm{mm}$ per day. The ET rates were simulated using daily time-steps then averaged for each month.

\subsection{CROPWAT Model}

The software program CROPWAT was developed by the Food and Agricultural Organization in 1998 (Allen et al., 1998) and revised in 2008. The purpose of this tool is to provide policy makers, analysts, and irrigation engineers with a practical set of information and calculations that guide the management of irrigated lands based on the response that crop yields will have to changes in the water budget. Given the ability to customize input parameters, such as the crop characteristics and the climatological data, CROPWAT is a powerful software that can aid the design of irrigation systems and improve current irrigation practices. This program is based on the ET of a reference crop, $E T_{o}$, to which ET for all other crops can be easily compared through the usage of crop specific coefficients (Section 2.4.1.3). The estimations of ET under different climate systems have typically required rigorous calibrations on the local-level yet are lacking on the global-stage. Testing the efficacy of these methods proved to be timeconsuming and costly, while the need for ET data is frequently required for the design of irrigation schedules and projects associated with them. A standard crop is desired to streamline the process of calculating ET for other crops in other climates. This standard crop is assumed to be grass, reaches a height of $0.12 \mathrm{~m}$, is disease-free, achieves full production due to sufficient fertilization and optimum soil-water conditions, and grows in a large field (Allen et al., 1998). The $E T_{o}$ is calculated based on the inputs to the climate and soil modules in CROPWAT. 


\subsubsection{CROPWAT Model: Input Requirements}

Though there are 5 input categories, or modules, available in CROPWAT -- climate, rainfall, soil, crop, and crop-patterning. Only the first four were required for this study.

\subsubsection{Climate and ETo Module}

The climate data required for the area of interest includes temperature $\left({ }^{\circ} \mathrm{C}\right)$, relative humidity $(\%)$, wind speed $\left(\mathrm{km} \mathrm{day}^{-1}\right)$, and hours of sun. The time-step can be monthly, daily or 10-day (1/3 month). For this project, the monthly time-step was chosen for simplicity. The spatial information needed is the altitude $(\mathrm{m})$ and latitude $\left({ }^{\circ} \mathrm{N}\right)$. Though longitudinal coordinates can be entered into this module, it is not necessary since only latitude is needed for calculating the solar radiation that reaches the earth's surface. Monthly averages for 2016 were used to reduce the number of input data points required.

The average temperature data was gathered from the National Oceanic and Atmospheric Administration (NOAA)'s National Centers for Environmental Information (NCEI) Climate Data Online Search (CDO) global summary of the month (NOAA, n.d., A). Stations that had the most complete set of data were selected, though preference was given to stations that were also near the center of the county. The output from user-specified search criteria shows the observed climatological data for each month, as well as the altitude, latitude, and longitude values for the station (Table 5). Relative humidity data was not available from the CDO, so it needed to be sourced from elsewhere. The lowa State University's archive of Automated Airport Weather Observations (AWOS or ASOS; ASOS, 2001) for Michigan and Indiana provided the relative humidity dataset based on a 10-minute interval observation period. Since investigating an entire year, data was averaged from collected observations for every third day, taken at 11:53 AM or 12:53 PM, whichever was first available. Note that Table 5 shows average temperature and humidity as an average for the growing season. A complete set of the temperature and humidity data can be found in the supplementary information (Tables A.1 and A.2). Wind speed was estimated from the monthly mean wind speed as shown on the NOAA's U.S. Wind Climatology dataset (NOAA, n.d., B) for 2016 by using the approximate location of the St. Joseph watershed (Table 6). The wind speed was assumed to be the same for each of the counties for simplicity.

Table 5. Weather Station data for each county in the St. Joseph watershed, climate data and station consulted for the 2016 observation year.

\begin{tabular}{|c|c|c|c|c|c|c|}
\hline State & County & Weather Station ID & Temperature $\left({ }^{\circ} \mathbf{F}\right)$ & Latitude ( $\left.{ }^{\circ} \mathbf{N}\right)$ & Altitude (m) & Humidity (\%) \\
\hline \multirow{5}{*}{ Michigan } & Berrien & USC00205892 & 67.58 & 41.84 & 198.12 & 60.83 \\
\cline { 2 - 7 } & Branch & USC00201675 & 65.60 & 41.96 & 299.92 & 58.67 \\
\cline { 2 - 7 } & Calhoun & USC00200552 & 66.00 & 42.37 & 281.33 & 62.83 \\
\cline { 2 - 7 } & Cass & USC00202250 & 54.78 & 41.99 & 225.55 & 66.50 \\
\cline { 2 - 7 } & Hillsdale & USC00203823 & 65.07 & 41.94 & 329.18 & 54.50 \\
\cline { 2 - 7 } & Kalamazoo & USW00094815 & 66.62 & 42.23 & 264.57 & 57.33 \\
\cline { 2 - 7 } & St. Joseph & USC00208184 & 65.32 & 41.93 & 246.89 & 62.17 \\
\cline { 2 - 7 } & Van Buren & USC00200864 & 65.12 & 42.38 & 224.33 & 66.17 \\
\hline & DeKalb & USC00123207 & 66.33 & 41.34 & 265.18 & 55.83 \\
\cline { 2 - 7 } & Elkhart & USC00123418 & 67.80 & 41.56 & 266.70 & 56.33 \\
\cline { 2 - 7 } & Kosciusko & USC00126400 & 67.15 & 41.36 & 289.86 & 60.83 \\
\cline { 2 - 7 } & LaGrange & Interpolated Data & 66.00 & 41.64 & 220.98 & 73.17 \\
\cline { 2 - 7 } & Noble & C62 & 67.88 & 41.47 & 304.41 & 76.00 \\
\cline { 2 - 7 } & St. Joseph & USW00014848 & 66.47 & 41.71 & 235.61 & 86.00 \\
\cline { 2 - 7 } & Steuben & USC00120200 & 65.32 & 41.66 & 310.90 & 70.17 \\
\hline
\end{tabular}


Table 6. Wind speed listed as the average for the month in 2016 and used as the monthly wind speed experienced across the entire watershed (NOAA, n.d., B).

\begin{tabular}{|c|c|}
\hline Month & $\begin{array}{c}\text { Wind Speed } \\
\text { (km day } \mathbf{~} \text { ) }\end{array}$ \\
\hline January & 398 \\
\hline February & 413 \\
\hline March & 440 \\
\hline April & 371 \\
\hline May & 371 \\
\hline June & 328 \\
\hline July & 344 \\
\hline August & 328 \\
\hline September & 371 \\
\hline October & 406 \\
\hline November & 425 \\
\hline December & 433 \\
\hline
\end{tabular}

Hours of sun (also called daylight hours), $N$, was not available in the CDO, so it was calculated using Equations 7 through 9 shown below (Allen et al., 1998), where $J$ is the day in the year (assumed to be the middle of each month), $\delta$ is the solar declination expressed as radians, and $\phi$ is the latitude expressed as radians. Table 7 shows the output from these calculations, with the example given for Berrien County, with data for the other counties listed in the supplementary information (Table A.4 and A.5). The solar radiation that reaches the earth's surface and the reference $\mathrm{ET}$ rate, $E T_{o}$, are calculated in the Climate/ET。 module based on these climate inputs.

$$
\begin{gathered}
\delta=0.409 * \sin \left(\frac{2 \pi J}{365}-1.39\right) \\
\omega_{s}=\arccos (-\tan \phi * \tan \delta) \\
N=\frac{24 * \omega_{s}}{\pi}
\end{gathered}
$$

\begin{tabular}{|c|c|c|c|c|c|c|}
\hline Month & J & $\delta$ & $\phi$ (degree) & $\phi$ (radians) & $\omega_{s}$ & $N$ \\
\hline January & 15 & -0.370 & \multirow{12}{*}{41.84} & \multirow{12}{*}{0.7302} & 1.216 & 9.3 \\
\hline February & 46 & -0.231 & & & 1.359 & 10.4 \\
\hline March & 75 & -0.042 & & & 1.533 & 11.7 \\
\hline April & 106 & 0.170 & & & 1.725 & 13.2 \\
\hline May & 136 & 0.331 & & & 1.884 & 14.4 \\
\hline June & 167 & 0.407 & & & 1.967 & 15.0 \\
\hline July & 197 & 0.373 & & & 1.929 & 14.7 \\
\hline August & 228 & 0.237 & & & 1.789 & 13.7 \\
\hline September & 259 & 0.035 & & & 1.602 & 12.2 \\
\hline October & 289 & -0.170 & & & 1.416 & 10.8 \\
\hline November & 320 & -0.335 & & & 1.253 & 9.6 \\
\hline December & 350 & -0.407 & & & 1.174 & 9.0 \\
\hline
\end{tabular}

Table 7. Required parameters for daylight hour calculations. 


\subsubsection{Rain Module}

This module requires only one set of input data: precipitation in units of millimeters. The output from this module is "effective rain", which is defined as the amount of precipitation that is available to be used by crops and vegetation, accounting for run-off and deep percolation. The default method in CROPWAT is the USDA Soil Conservation Service (SCS) Method and was not modified for this study. Month-averaged precipitation data was collected from the NOAA CDO portal, with Table 8 providing the average rainfall occurring during the growing season. Table A.3 provides the precipitation occurring during each month of the analysis year for each county in the watershed.

Table 8. Precipitation data for 2016 growing season of each county.

\begin{tabular}{|c|c|c|}
\hline State & County & Precipitation (in) \\
\hline \multirow{4}{*}{ Michigan } & 5.26 \\
\cline { 2 - 3 } & Berrien & 3.21 \\
\cline { 2 - 3 } & Branch & 3.75 \\
\cline { 2 - 3 } & Calhoun & 4.67 \\
\cline { 2 - 3 } & Cass & 3.18 \\
\cline { 2 - 3 } & Hillsdale & 4.46 \\
\cline { 2 - 3 } & Kalamazoo & 4.76 \\
\cline { 2 - 3 } & St. Joseph & 4.43 \\
\cline { 2 - 3 } & Van Buren & 3.47 \\
\hline \multirow{4}{*}{ Indiana } & DeKalb & 3.95 \\
\cline { 2 - 3 } & Elkhart & 3.58 \\
\cline { 2 - 3 } & Kosciusko & 3.29 \\
\cline { 2 - 3 } & LaGrange & 3.25 \\
\cline { 2 - 3 } & Noble & 4.84 \\
\cline { 2 - 3 } & St. Joseph & 3.60 \\
\cline { 2 - 3 } & Steuben & \\
\hline
\end{tabular}

\subsubsection{Crop Module}

The evapotranspiration of crops investigated in CROPWAT are related to the reference crop through the usage of crop coefficients (Equation 10).

$$
E T_{C}=K_{C} * E T_{o}
$$

The crop coefficient, $K_{c}$, is specific to each crop, representing the crop's transpiration and characteristics that incorporate the averaged effects of soil evaporation. There are three $K_{c}$ values -- initial, mid-season, and late-season -- that are specific to the growth stages of the crop. Stage refers to the periods in vegetation's life that have distinct growth rates. Critical depletion fraction, $p$, is the average fraction of the total available soil water at the root zone that can be removed from the soil before water stress occurs and ET is reduced. Like the $K_{c}$ and the growth stages, $p$ is specific to each crop, though values ranging from 0.4-0.6 are most used for many crops. Yield response factor, $K_{y}$, describes the reduction in crop yield that would be experienced if there were water shortages in the soil layers that causes a reduction in the crop's ET, and vary over the growing season. Crop height is the maximum height that the crop can reach if ideal growing conditions are experienced and that fit within the bounds of the crop's genetic makeup. Maximum rooting depth is like the crop height in that it is specific to the crop's genetic makeup as well as the growing conditions. The planting and harvest dates are sourced from Usual Planting and Harvesting Dates for U.S. Field Crops (NASS, 2010), with the mid-point used for the "most active" period. The values shown in Table 9 come directly from CROPWAT's ready-made crop files. 
Table 9. Crop characteristics for maize and soybeans (Allen, 1998) as well as the usual planting \& harvest dates (NASS, 2010).

\begin{tabular}{|c|c|c|c|c|c|c|c|}
\hline \multirow{2}{*}{ Crop } & \multicolumn{3}{|c|}{$\mathrm{K}_{\mathbf{C}}$} & \multicolumn{4}{|c|}{ Stage (Days) } \\
\hline & Initial & Mid. & Late & Initial & Dev. & Mid. & Late \\
\hline Maize & 0.30 & 1.20 & 0.35 & 20 & 35 & 40 & 30 \\
\hline Soybeans & 0.40 & 1.15 & 0.50 & 15 & 15 & 40 & 15 \\
\hline \multirow{2}{*}{ Crop } & \multicolumn{3}{|c|}{ Critical Depletion Fraction } & \multicolumn{4}{|c|}{ Yield Response Factor } \\
\hline & Initial & Mid. & Late & Initial & Dev. & Mid. & Late \\
\hline Maize & 0.55 & 0.55 & 0.80 & 0.40 & 0.40 & 1.30 & 0.50 \\
\hline Soybeans & 0.50 & 0.60 & 0.90 & 0.40 & 0.80 & 1.00 & 0.40 \\
\hline Crop & \multicolumn{3}{|c|}{ Crop Height (m) } & \multicolumn{4}{|c|}{ Maximum Rooting Depth $(\mathrm{m})$} \\
\hline Maize & \multicolumn{3}{|c|}{2.00} & \multicolumn{4}{|c|}{1.00} \\
\hline Soybeans & \multicolumn{3}{|c|}{0.75} & \multicolumn{4}{|c|}{0.95} \\
\hline Crop & \multicolumn{3}{|c|}{ Planting Date } & \multicolumn{4}{|c|}{ Harvest Date } \\
\hline Maize & \multicolumn{3}{|c|}{ May $15^{\text {th }}(\mathrm{MI})$, May $17^{\text {th }}(\mathrm{IN})$} & \multicolumn{4}{|c|}{ Oct. $21^{\text {St }}(\mathrm{MI})$, Nov. $2^{\text {nd }}(\mathrm{IN})$} \\
\hline Soybeans & \multicolumn{3}{|c|}{ May $25^{\text {th }}(\mathrm{MI})$, May $27^{\text {th }}(\mathrm{IN})$} & \multicolumn{4}{|c|}{ Oct. $16^{\text {th }}(\mathrm{MI})$, Oct. $18^{\text {th }}(\mathrm{IN})$} \\
\hline
\end{tabular}

\subsubsection{Soil Module}

Before selecting a soil type to simulate in CROPWAT, the soil types found within the St. Joseph watershed need to be understood. There are many ways to classify the soil profiles, with two common classifications being hydrologic soil group and soil drainage class. Hydrologic soil groups are based the potential the soils have to experiencing runoff, as well as the infiltration rates that can be expected. These groups are ranked by letters $A$ through $D$, where $A$ has the smallest runoff potential and $D$ has the greatest potential.

\subsection{Hydrologic Soil Groups}

The most common hydrologic group in the watershed is A, covering $31.84 \%$ of the watershed. Figure 4 provides orientation to how the soil groups are spatially distributed. Table 10 shows the percentage breakdown of these soil groups present in the St. Joseph watershed. In addition, using the CDLs discussed above, hydrologic soil groups were further analyzed to understand the relationship between the vegetation grown and the soil groups (Table 10). From this, it is shown that maize, soybeans, and deciduous forests are being cultivated or grown primarily on hydrologic soil group $A$.

Table 10. Percentage of each hydrologic soil group that can be found in the watershed.

\begin{tabular}{|c|c|c|c|c|c|}
\hline Hydrologic Soil Group & Acreage & $\begin{array}{c}\text { \% Of } \\
\text { Watershed }\end{array}$ & $\begin{array}{c}\text { Maize } \\
\text { Cropland, \% }\end{array}$ & $\begin{array}{c}\text { Soybean } \\
\text { Cropland, \% }\end{array}$ & $\begin{array}{c}\text { Deciduous } \\
\text { Forest, \% }\end{array}$ \\
\hline A & $1,641,371$ & 31.8 & 30 & 26 & 37 \\
\hline B & 984,167 & 19.1 & 23 & 25 & 16 \\
\hline C & 584,593 & 11.3 & 14 & 14 & 11 \\
\hline D & 71,020 & 1.4 & 1 & 2 & 1 \\
\hline A/D & 768,047 & 14.9 & 9 & 7 & 15 \\
\hline B/D & 609,735 & 11.8 & 14 & 15 & 11 \\
\hline C/D & 496,121 & 9.6 & 10 & 12 & 8 \\
\hline
\end{tabular}




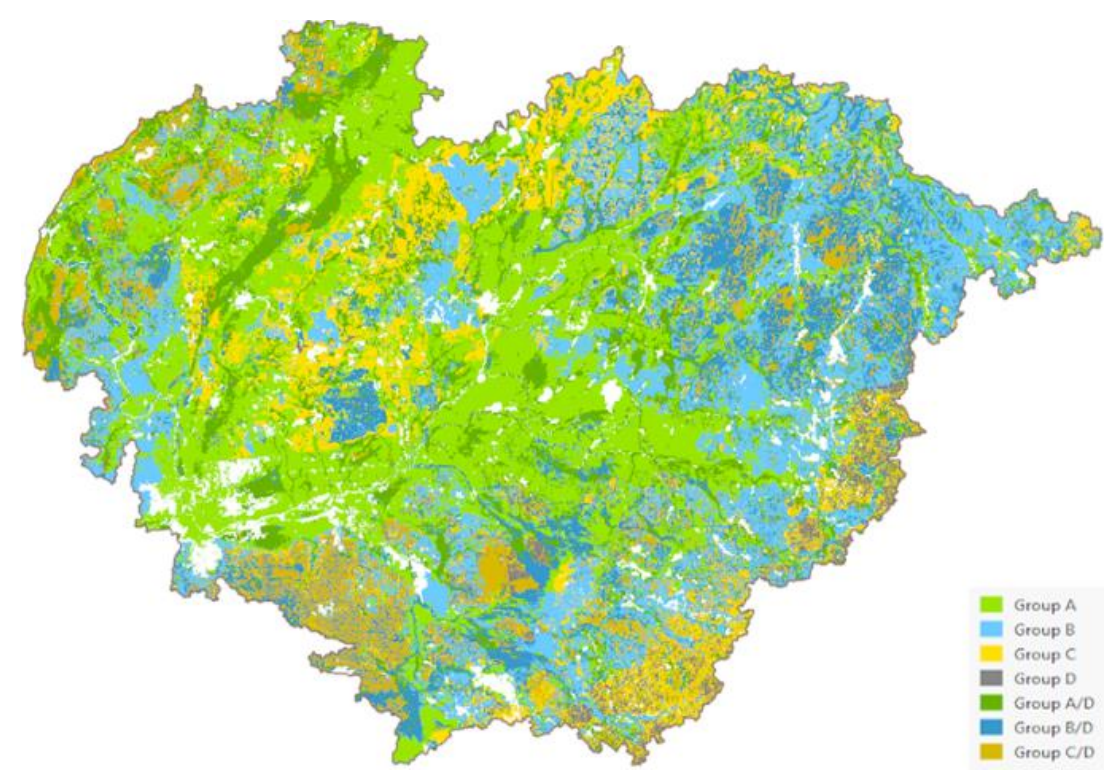

Figure 4. Hydrologic soil groups in the St. Joseph watershed at spatial resolution of 30-meters (NRCS, 2020A).

\subsection{Soil Drainage Classes}

Soil types can also be described by soil drainage classes, which describe the frequency and duration for which these soils are wet. There are seven classes of natural soil drainage that are widely recognized: excessively drained, somewhat excessively drained, well drained, moderately well drained, somewhat poorly drained, poorly drained, and very poorly drained. Figure 5 shows how the soil drainage categories vary across the St. Joseph watershed, as mapped in ArcGIS Pro, with Table 11 documenting the acreage and percentage of the watershed that each class is represented. From this soil investigation, it is verified that the well-drained soil group best represents the watershed.

Table 11. Area of the St. Joseph watershed comprised of various soil drainage classes, with the simplified classes being the summation of similar classes' surface area.

\begin{tabular}{|c|c|c|}
\hline Soil Drainage Class & Acres & \% \\
\hline Excessively Drained & 21,633 & 3.55 \\
\hline Somewhat Excessively Drained & 96,592 & 1.89 \\
\hline Well Drained & $2,566,136$ & 50.18 \\
\hline Moderately Well Drained & 360,462 & 7.05 \\
\hline Somewhat Poorly Drained & 775,061 & 15.16 \\
\hline Poorly Drained & 559,607 & 10.94 \\
\hline Very Poorly Drained & 574,452 & 11.23 \\
\hline
\end{tabular}




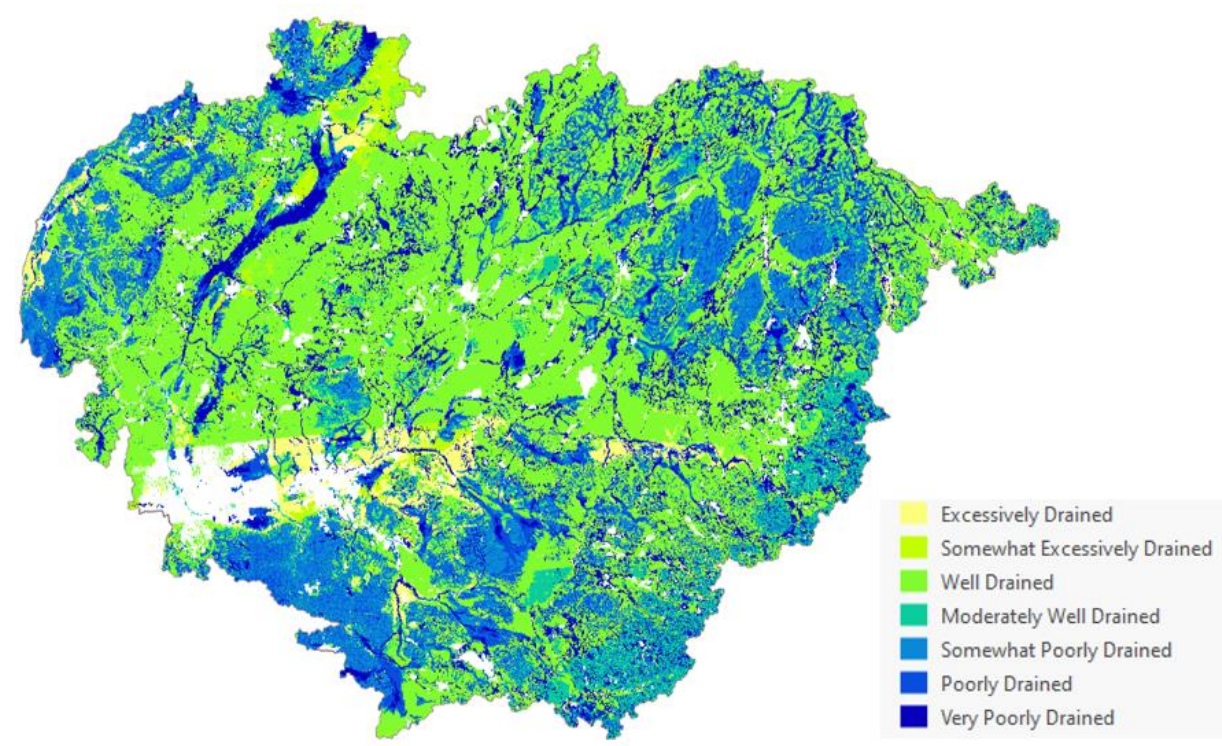

Figure 5. Distribution of soil drainage classes across the watershed at spatial resolution of 30-meters (NRCS, 2020B).

\subsection{Simulated Soil Types}

With the soil type defined for the watershed, inputs to the final module "soil" can now be discussed. There are three default soil files that are available in CROPWAT -- light, medium, and heavy soils (Table 12). Light soil refers those that are permeable and well-drained, like sands or silts. Medium soils are dominated by loam, while heavy soils are composed of clay and poorly drained soil types. The alignment between hydrologic soil group A and well-drained soil classes being the dominant soil categories in the St. Joseph watershed support using light soil in CROPWAT as a representative soil type. However, as shown in Figures 4 and 5, many soil types exist in the watershed. Thus, the water footprint will be simulated using all available soil types in CROPWAT to better understand the response of the water budget to production of maize and soybeans on these different soil types.

Customizable soil parameters in CROPWAT include the total available soil moisture (TAM, $\mathrm{mm} \mathrm{m}^{-1}$ ), maximum rain infiltration rate $\left(\mathrm{mm} \mathrm{day}^{-1}\right)$, maximum rooting depth $(\mathrm{cm})$, and initial soil moisture depletion (\% of the TAM). Total available water is the total amount of water that is readily available for crop usage and is the difference between the field capacity and the wilting point. Field capacity is the total water that soils can contain at saturation, after excess water has drained by gravity. Wilting point, also referred to as the permanent wilting point, is defined as the point at which soils no longer hold water that can be extracted. The maximum rain infiltration rate is the depth of water that permeates the soil over a 24-hour period. While the maximum rooting depth in Table 9 is specific to the crop itself, the maximum rooting depth of the soil is the depth at which all crops can penetrate the soil as characteristic of the soil itself, rather than the genetic makeup of the crop. This value is arbitrarily set to a default value of $900 \mathrm{~cm}$ for each soil type since it indicates that there are no significant characteristics that would limit root growth. The initial soil moisture depletion, or the dryness of the soil at the beginning of the growing season, is defaulted to $0 \%$ to represent that the soil is at field capacity. The output is the initial available soil moisture $\left(\mathrm{mm} \mathrm{m}^{-1}\right)$, which represents the water content of the soil at the beginning of the growing season and is the product of TAM and initial soil moisture depletion. 
Table 12. Soil characteristics based on soil files in CROPWAT.

\begin{tabular}{|c|c|c|c|c|c|}
\hline Soil Type & $\operatorname{TAM}\left(\mathrm{mm} \mathrm{m}^{-1}\right)$ & $\begin{array}{l}\text { Maximum Rain Infiltration } \\
\text { Rate }\left(\mathrm{mm} \text { day }^{-1}\right)\end{array}$ & $\begin{array}{l}\text { Maximum Rooting } \\
\text { Depth }(\mathrm{cm})\end{array}$ & $\begin{array}{c}\text { Initial Soil } \\
\text { Moisture } \\
\text { Depletion (\%) }\end{array}$ & $\begin{array}{c}\text { Initial Available } \\
\text { Soil Moisture } \\
\left(\mathrm{mm} \mathrm{m}^{-1}\right)\end{array}$ \\
\hline Light & 60 & 40 & 900 & 0 & 60 \\
\hline Medium & 290 & 40 & 900 & 0 & 290 \\
\hline Heavy & 200 & 40 & 900 & 0 & 200 \\
\hline
\end{tabular}

\subsubsection{CROPWAT Model: Output Modules}

There are two ways to estimate the green and blue water ET rates in CROPWAT: crop water requirements (CWR) and irrigation scheduling (IS).

\subsubsection{Crop Water Requirements (CWR)}

The first method is the crop water requirement (CWR). From this module, the user is assuming that the crops of interest are growing under optimal conditions, which are the same as those specified for the reference crop. It was discovered during simulations that CROPWAT does not require soil inputs for the CWR module to calculate crop water use, only climate and crop modules are needed. Appendix B shows the manipulations made to crop variables that are dependent or partially dependent on soil type, and the resulting ET rates, in an attempt to account for the exclusion of soil characteristics. This suggests that the ET rates, and thereby the water footprint calculations, may not be accurately represented. Therefore, only the irrigation schedule option, which does incorporate soil type into the calculations, will be used to calculate green and blue ET rates for this study.

\subsubsection{Irrigation Scheduling (IS)}

The scheduling module is used to 1 ) evaluate the production of crops in rainfed scenarios (no irrigation), 2) assess the necessity of irrigation to supplement the water demands and 3) understand the efficiency of current irrigation practices. There are several irrigation options for timing and applications patterns to choose from in the IS module; however, "irrigation at critical depletion" (timing) and "refilling the soil to field capacity" (application) were the two options selected for this study. Irrigating at critical depletion means that irrigation will occur once the soil's readily available water reaches zero and is the traditional approach to determining irrigation schedules. Refilling at soil field capacity is a default parameter in CROPWAT and was not altered during the simulations. These choices are the default options in the IS module and assumes that irrigation is optimal with no crop stress and the frequency of irrigation is at maximum intervals. The rainfed scenario will also be simulated since it represents an agricultural system that relies only on green water sources for successful crop development.

Various parameters calculated in the IS module are of importance: total gross irrigation, total net irrigation, actual water use by crop, and actual irrigation requirement. Total gross irrigation is water depth applied to the field. The total net irrigation represents the fraction of the total gross irrigation that effectively reaches the crop's root zone. The actual water use by the crop represents the total water that has evaporated over the growing period, and the actual irrigation requirement is the depth of water needed for successful plant growth based on the climatological inputs. Consumptive use of blue water resources is calculated as the minimum value between the total net irrigation and actual irrigation requirement (Equation 11). Green ET rates for both scenarios -- irrigation at critical depletion and rainfed - is the difference between the actual water use by the crop, $E T_{a}$ and the blue water consumed (Equation 12). Blue water withdrawals are represented by the total gross irrigation depth. Since irrigation water 
depends on rainfall patterns for each growing season, understanding the water withdrawals, or the total volume of water removed from a water body, quantifying this in an important aspect of the understanding the impact that water-intensive crops have on freshwater resources.

$$
\begin{gathered}
E T_{\text {blue }}=\min (\text { Total Net Irrigation, Actual Irrigation Requirement }) \\
E T_{\text {green }}=E T_{a}-E T_{\text {blue }}
\end{gathered}
$$

\subsection{Comparison of Models Used}

With CROPWAT and HAWQS now described, it is important to point out the similarities and differences between these models. The Penman-Monteith equation is used for calculating potential ET rates for both models (calculated as ETo in CROPWAT). This equation is widely recognized as a superior method for quantifying ET rates since it relies on climatological inputs and is thereby spatially and temporally explicit. However, HAWQS is considered to be the more geospatially referenced model due to the fact that land use categories and soil types are inputs to the model allowing it to simulate the water demands of a watershed. CROPWAT, on the other hand, is designed to model smaller spatial units, such as an acre of cropland at a specific location.

If not executing multiple simulations with the different soil types available in CROPWAT, the user needs to make assumptions about the soils found in the area of interest. For this study, the soils that are available in CROPWAT were used, and thus soils that are a combination of more than one soil type (such as a mixture of sands and loam, or a mixture of loam and clay) are not simulated. Though there is an ability to customize the soil characteristics as described in Section 2.4.1.4.3, this information is not readily available. Furthermore, though soil types might be similar in composition, the characteristics might differ slightly. For example, if a soil is considered to be a mixture of light and medium soils, the TAM may be a value of $200 \mathrm{~mm} \mathrm{~m}^{-1}$; however, it might be found that elsewhere in the watershed, this same soil mixture has a TAM of $210 \mathrm{~mm} \mathrm{~m}^{-1}$. A scenario like this would require the user to perform multiple simulations in CROPWAT. HAWQS, on the other hand, considers these spatially variable soil combinations during the modeling process.

Both models can simulate daily and monthly time-steps. However, users may find that the HAWQS model is easier to use at the daily level. For an entire year and for multiple locations, as analyzed in this study, using CROPWAT may be too cumbersome since it requires manual data entries. Data collection itself at the daily-level may also be too laborious and require assumptions and estimates if data is missing. HAWQS alleviates these data entry and collection issues by having drop-down menus of sources from which data can be automatically input to the model.

If not familiar with SWAT, the core modeling engine for HAWQS, users may not fully grasp the background calculations in the model, as described in the SWAT documentation (Neitsch et al., 2011). Conversely, CROPWAT requires the user to input data step-by-step, filling in one module with data at a time. The output calculations are shown in the manual, and output calculations appear immediately after filling in data. For example, in the soil module, once the first four cells are filled with a value, the initial available soil moisture is shown. 


\subsection{Gray Water Footprint}

In the context of this study, the gray water footprint represents the amount of freshwater needed to reduce (dilute) phosphorus pollution associated with the production of agricultural products within a watershed. Data on the application rates of fertilizers that contain phosphorus was sourced from the USDA's Economic Research Service (ERS) Fertilizer Use and Price database (ERS, 2019). Though the data is not broken down by county, there are statewide averages listed for several states. In this dataset, tables that list the weight of phosphate fertilizers (in pounds) that were applied to maize and soybeans cropland (acres) were consulted. For soybeans, data for 2016 was not available, and thus 2017 values were used. The leaching-runoff fraction for phosphorus ranges from 0.0001 to 0.05 , where the mid-range fraction of 0.03 was used in this study (Franke et al., 2013). Local data is not available for this value; thus, this value was selected despite it being derived from global data. Additionally, there was no distinction between the leaching-runoff fraction for various soil types.

The natural concentration of phosphorus is not always known and is the case for the St. Joseph watershed. The St. Joseph River was investigated for nutrient pollution (Matousek, 2010). There is no other source of information regarding the natural concentration of nutrients in the watershed itself, other than stream monitoring studies, meaning that using these findings to inform this study will not be representative of the watershed as whole. Typically, if the pollutant is synthetic or has a percentage of synthetic compounds in it, the natural concentration is assumed to be zero. However, with substances that are found in the natural environment, such as nutrients like nitrogen and phosphorus, the same assumption is not always appropriate since it may skew the gray water footprint value in a way that overestimates the actual impact of the pollutant. Even with low levels of nutrients in freshwater bodies (surface and ground waters), there can be serious environmental and human health issues present. Despite the issues discussed, the natural concentration of phosphorus will be set to zero. The Michigan Department of Environmental Quality (MDEQ) states that the regulatory limit for phosphorus in rivers is $0.03 \mathrm{mg} \mathrm{L}^{-1}$ and will be used for $c_{\max }$ (MDEQ, 2010).

Fertilizers are expressed in terms of weight percentages of elements such as nitrogen and phosphorus. Common phosphate fertilizers are composed of approximately $44 \%$ of elemental phosphorus (Baker et al., 2002). Depending on the source of the phosphate (such as monoammonium phosphate (MAP) or ammonium polyphosphate (APP)), the percentage that is water soluble varies. For example, if phosphate is sourced from MAP, $48.5 \%$ is water-soluble; if sourced from APP, then $34 \%$ is water-soluble (University of Minnesota, 2018). For the purpose of this study, the average of these percentages $-40 \%$-- will be used since the exact type of phosphate fertilizer is not known. The phosphate fertilizer application rates will be multiplied by percent of elemental phosphorus and percent of water solubility to provide the application rate of elemental phosphorus. 


\section{Results and Discussion}

\subsection{Baseline Water Footprint}

From the HAWQS model, ET rates were calculated for each day of the analysis year in units of mm day ${ }^{-1}$. These are converted into crop water use (CWU) terms for the growing season to units of $\mathrm{m}^{3}$ hectare $\mathrm{e}^{-1}$ using the Equation 13. Results for each month are shown in Table 13. The growing season CWU for deciduous trees is $3452 \mathrm{~m}^{3}$ hectare ${ }^{-1}$. Since the Hamilton et al. (2018) study outputs only one value for the growing season ET, the CWU from this study is calculated to be $3738 \mathrm{~m}^{3}$ hectare $\mathrm{e}^{-1}$. Thus, in Figure 6 , the Hamilton value is assumed constant over the analysis year, while the HAWQS values are different for each month.

$$
C W U=\sum E T * 10 \frac{m^{3}}{h a * m m} * 30.48 \frac{\text { day }}{\text { month }}
$$

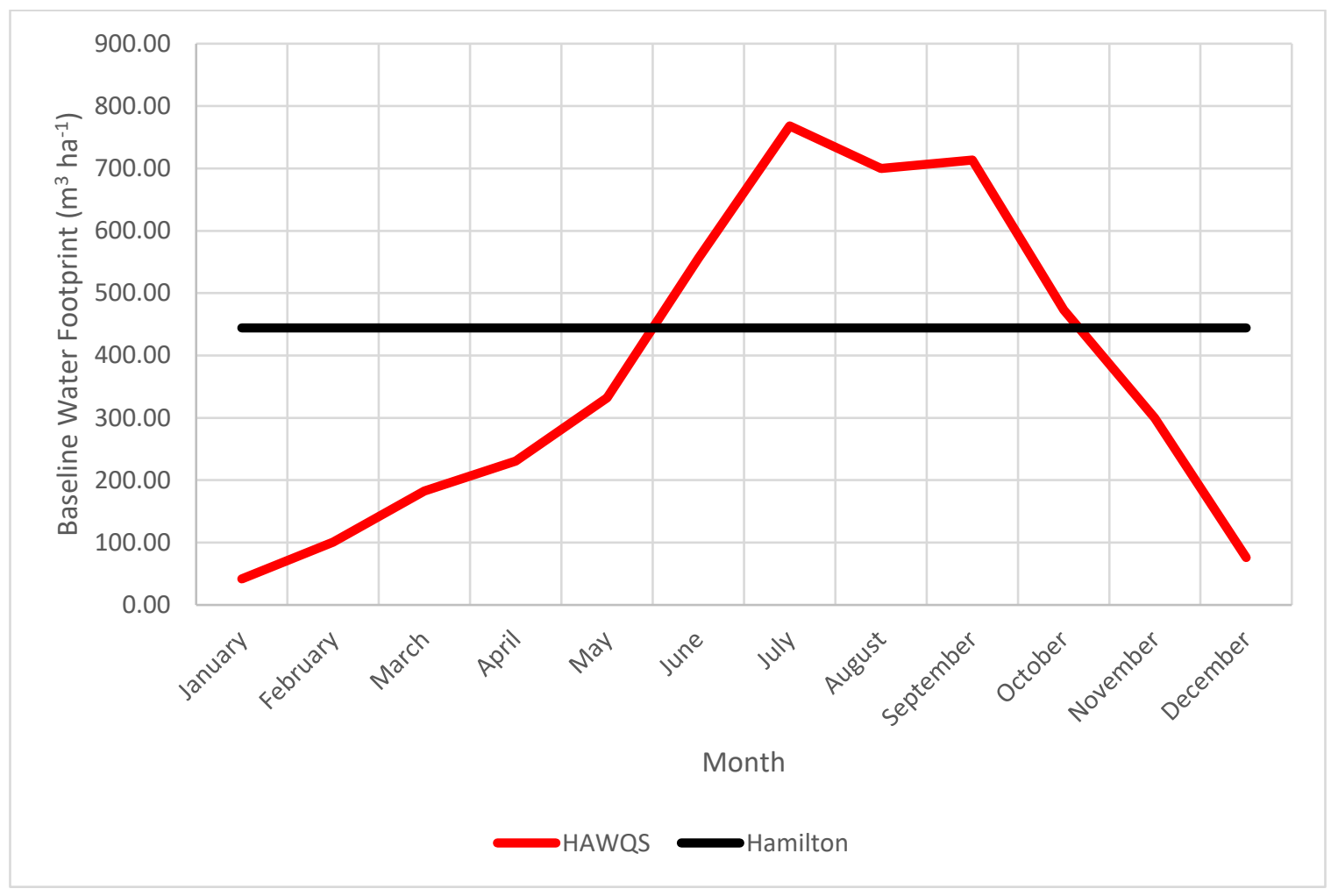

Figure 6. Comparison of source for baseline ET rates baseline water footprints 
Table 13. Conversion of HAWQS model output ( $\mathrm{mm}$ day $\mathrm{y}^{-1}$ ) to crop water use terms (units of $\mathrm{m}^{3}$ hectare-1)

\begin{tabular}{|c|c|c|}
\hline Month & $\begin{array}{l}\text { Evapotranspiration } \\
\text { Rate }\left(\mathrm{mm} \text { day }^{-1}\right)\end{array}$ & $\begin{array}{c}\text { Crop Water Use } \\
\left(\mathrm{m}^{3} \text { hectare }^{-1}\right)\end{array}$ \\
\hline January & 0.14 & 41.8 \\
\hline February & 0.33 & 100.8 \\
\hline March & 0.60 & 182.9 \\
\hline April & 0.76 & 230.9 \\
\hline May & 1.09 & 332.0 \\
\hline June & 1.82 & 556.0 \\
\hline July & 2.52 & 768.1 \\
\hline August & 2.30 & 699.9 \\
\hline September & 2.34 & 713.1 \\
\hline October & 1.55 & 473.1 \\
\hline November & 0.98 & 299.7 \\
\hline December & 0.25 & 76.3 \\
\hline
\end{tabular}

\subsection{Blue Water Footprint}

Consumptive use of blue water resources means that the water has transpired, is incorporated into a crop, does not return to the watershed, or will return during a different period. The IS module calculates the ET associated with consumption, $E T_{\text {blue }}$, using Equation 11 for the "irrigation at critical depletion" scenario; blue water use is zero for the rainfed scenario since no irrigation occurs. To calculate the blue water footprint, Equation 3 is employed, where the yield for maize and soybeans for each county of the St. Joseph watershed comes from Table 4.

Figure 7 shows the consumptive water footprint for each county in the watershed in 2016 simulated for each soil type. For both maize and soybeans, the consumption of blue water resources is highest when crops are cultivated on light soils. With the representative soil type of the St. Joseph watershed being light soils, producing water-intensive crops on this soil type raises concerns regarding the agricultural management decisions. Medium soils generally have the lowest consumptive footprint, with the exceptions being soybeans grown in DeKalb County and both crops grown in Berrien, St. Joseph (MI), Kosciusko, and LaGrange counties. These exceptions are the result of variable rainfall patterns during the 2016 growing season.

Cass County experiences the lowest consumptive blue water footprint for the cultivation of both maize and soybeans. For the three soil types simulated, the total net irrigation was calculated to be $54.1 \mathrm{~mm}$ for light soils and $0 \mathrm{~mm}$ for medium and heavy soils. The actual irrigation requirement was also small: 64.6 $\mathrm{mm}$ for light soils, $6.4 \mathrm{~mm}$ for medium soils, and $13 \mathrm{~mm}$ for heavy soils. This translates into very small blue water ET rates and thereby small blue water footprints. These results suggest that the seasonal rainfall essentially met the water requirements of the crop. 


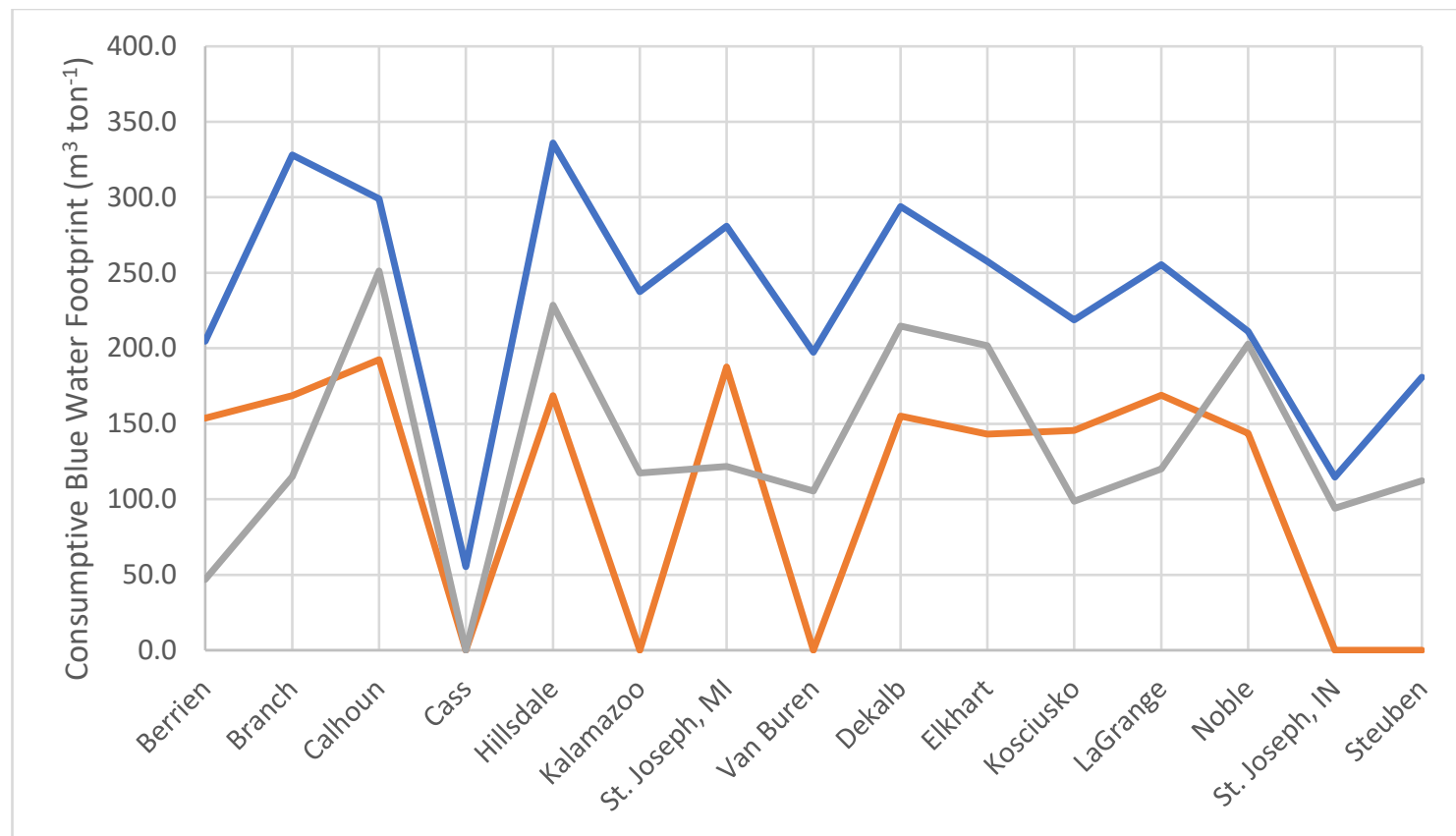

County in St. Joseph Watershed
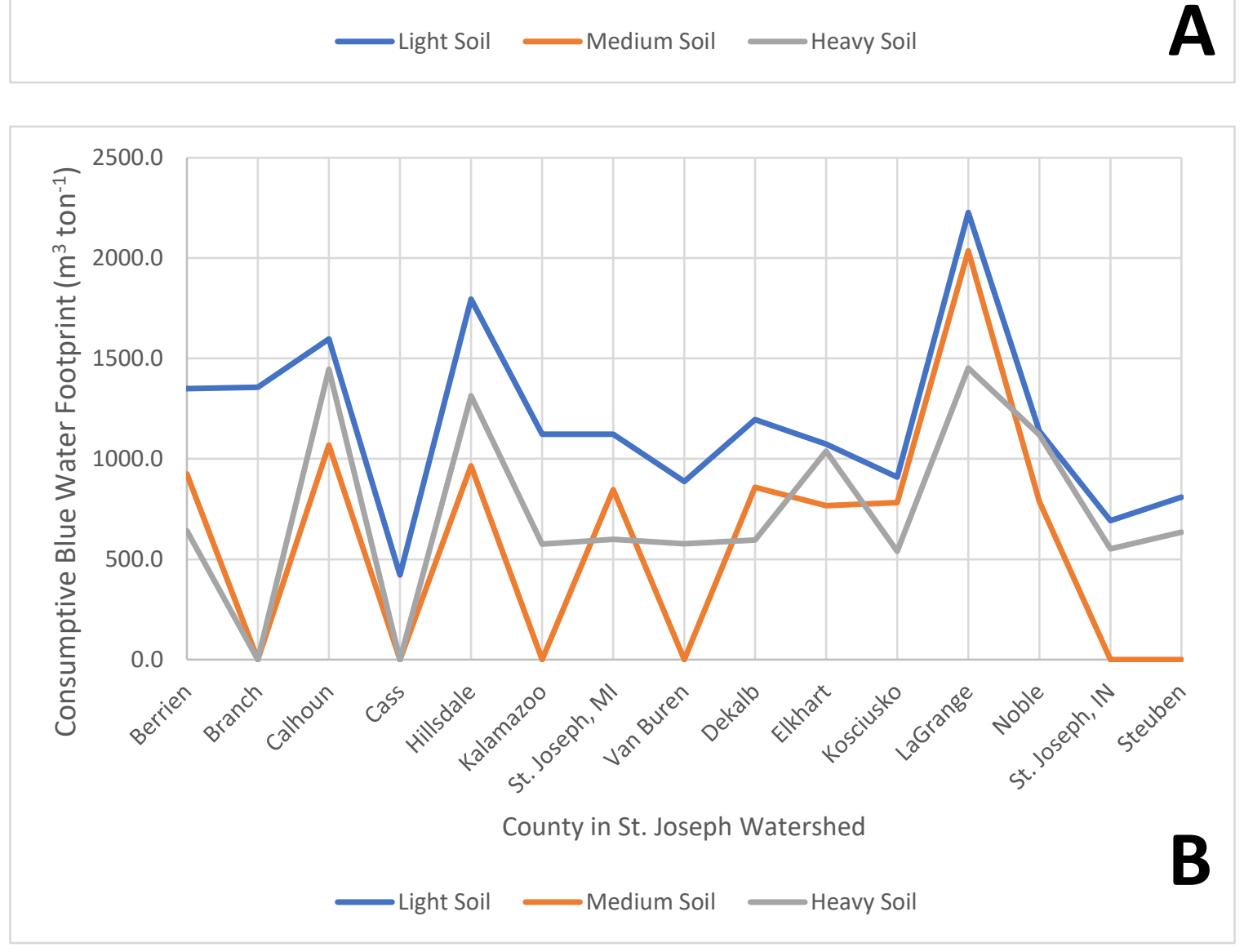

Figure 7. Consumptive blue water footprint calculated from the irrigation at critical depletion simulated with maize (A) and soybeans (B) for the 2016 growing season 


\subsection{Withdrawal of Blue Water}

Blue water withdrawal is an important aspect watershed resource management, since it represents the total amount of water removed from a natural water source. Typically considered for watershed management in terms of permitting, the withdrawal values can be used to better understand how agricultural practices impact the local landscape's water budget. The IS method provides the blue water withdrawal as the total gross irrigation and is a function of the crop yield and the effective rainfall. Because of this, the precipitation data was averaged over the growing season, which roughly occurs between the months of May to October, as shown in Table 8.

In Figure 8, the rainfall pattern experienced in Cass County for 2016 was the most favorable for production of the two agricultural products selected, since it has smallest water withdrawal for each soil type simulated. In contrast, LaGrange County requires the greatest amount of water to be withdrawn, suggesting more water is needed from blue water sources to counteract depletions in soil moisture occurring over the growing season.. Generally, light soils are the most sensitive to the rainfall patterns, as evident in large footprint calculated for each county and for each crop. The lowest withdrawals are seen when the agricultural activities are occurring on medium soils. 


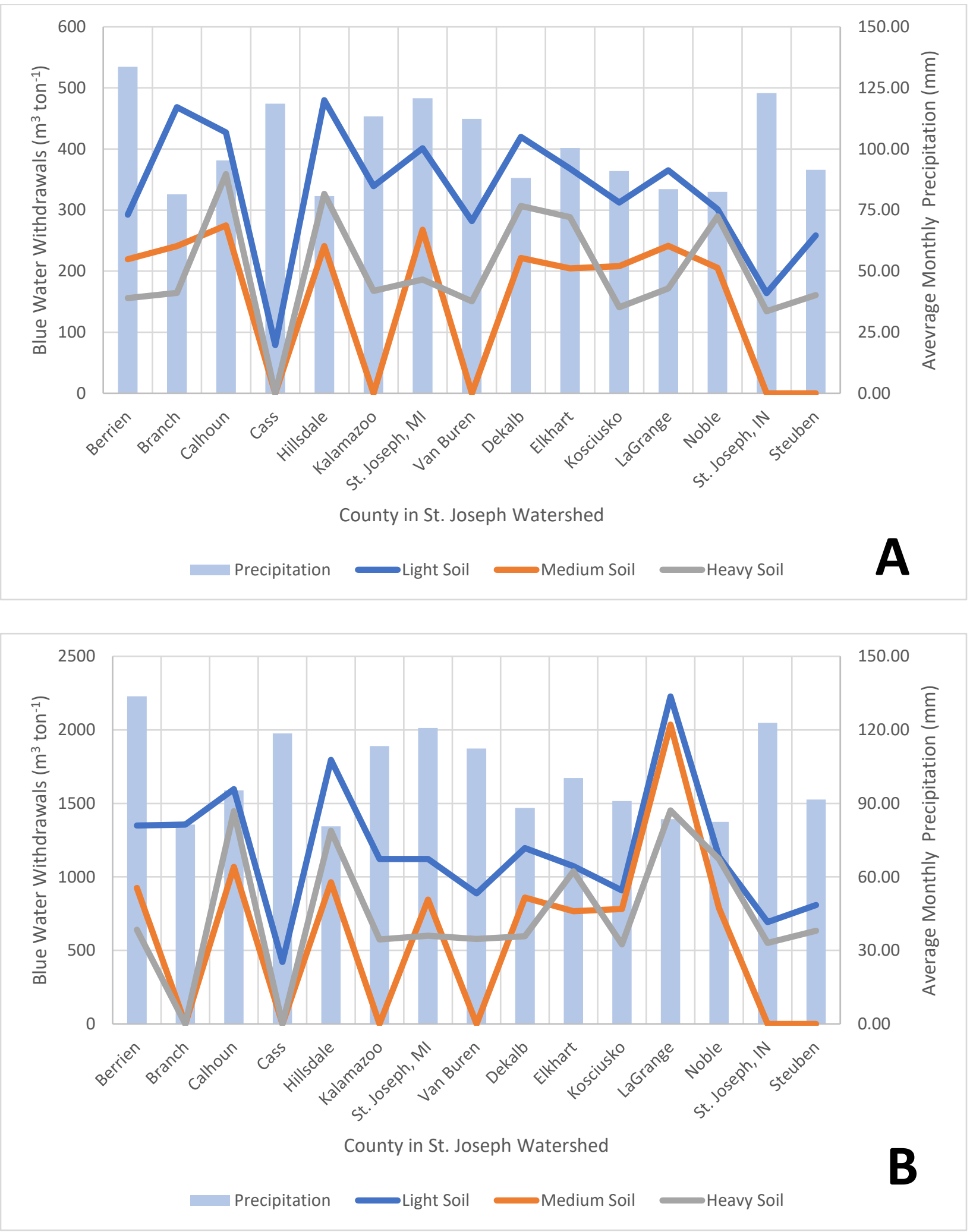

Figure 8. Withdrawal blue water footprint calculated from simulating irrigation at critical depletion with maize (A) and soybeans (B). 


\subsection{Green Water Footprint}

For both the "irrigation at critical depletion" and "rainfed" scenarios, the green water footprint requires the greatest amount of green water resources for cultivation on medium soils, while light soils require the smallest amount of rainwater (Figure 9). The rainfed scenario outputs the largest values of the green water footprint, which makes sense since the background assumption is the crops are using only green water, as opposed to a combination of blue and green water as modeled in the "irrigation at critical depletion" option. In the subsequent analysis, the green water footprint values will be sourced from the "irrigation at critical depletion" scenario. This is because it accounts for blue and green water uses, which is considered to be more representative of agricultural systems in the Midwest. 


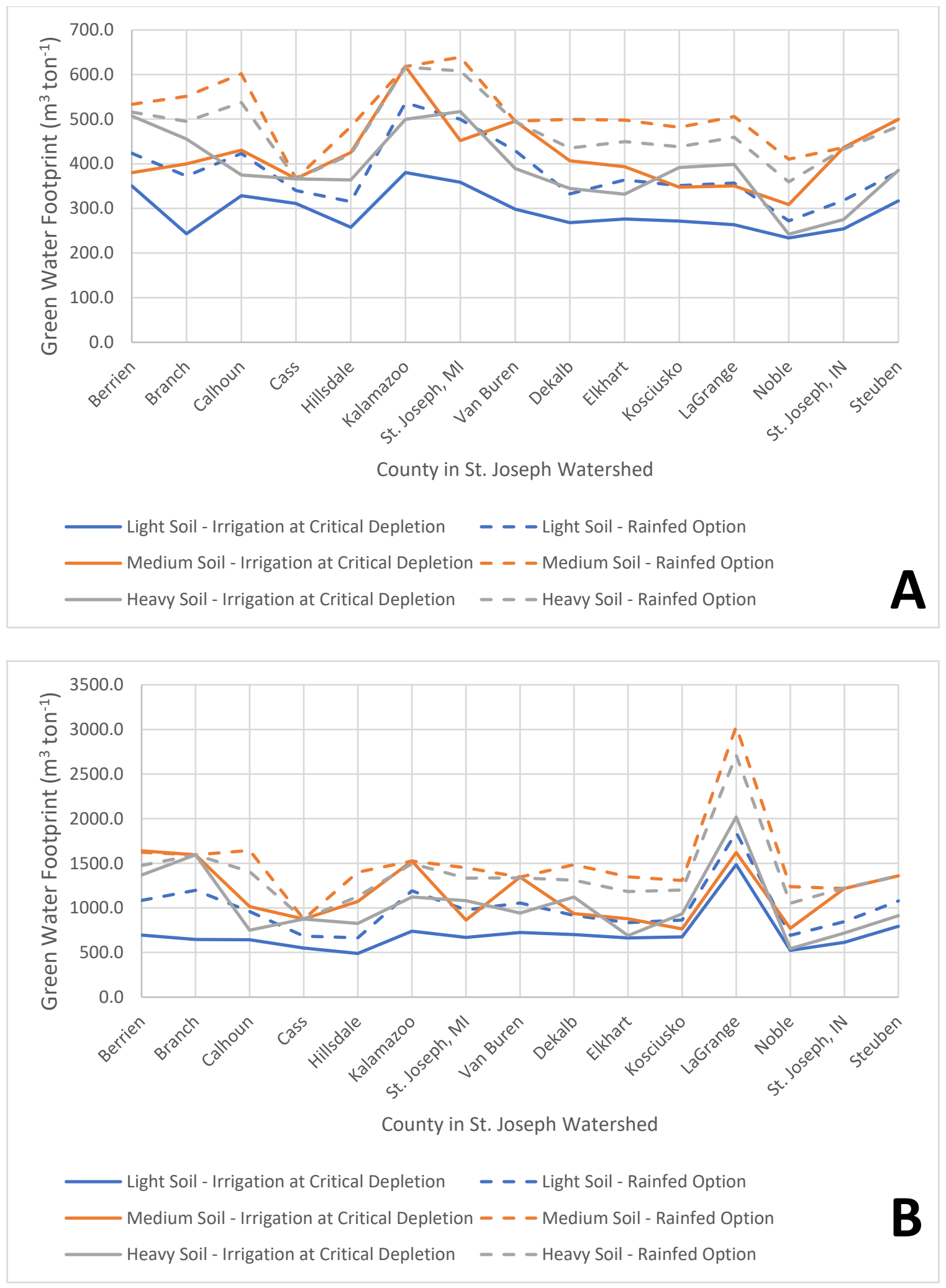

Figure 9. Green water footprints using the two irrigation scheduling options for maize (A) and soybeans (B). 


\subsection{Gray Water Footprint}

Of all the water footprint components, the gray water footprint is the largest. Using Equation 4, the gray water footprint values for maize and soybeans are shown in Table 14. Here we see that counties in Indiana had larger gray water footprints for maize and soybeans than those of Michigan counties (Figure 10). An explanation for this is the application rates of phosphate fertilizers. For the state of Indiana, 74 pounds of fertilizer are applied to each acre of maize, while only 43 pounds are applied per acre of maize in Michigan, on average. Farms in Indiana apply an average of 62 pounds of phosphate fertilizers to soybean-cultivated lands, while Michigan farms apply an average of 44 pounds per acre (ERS, 2019). Van Buren County and DeKalb County had similar yields of maize (approximately 172,000 tons), as well as number of acres planted (about 40,000 acres). However, because of the large difference between the application rates, the resulting gray water footprints were significantly different $-799 \mathrm{~m}^{3}$ ton $^{-1}$ for Van Buren County versus $1372 \mathrm{~m}^{3}$ ton $^{-1}$ for DeKalb County. This suggests the need for county-specific data, rather than state averages like those used in this study.

Table 14. Acres planted and harvested volume of agricultural crops in the St. Joseph watershed, with estimated application rate of phosphorus and calculated gray water footprint.

\begin{tabular}{|c|c|c|c|c|c|c|c|c|c|}
\hline \multirow[b]{2}{*}{ State } & \multirow[b]{2}{*}{ County } & \multicolumn{4}{|c|}{ Maize } & \multicolumn{4}{|c|}{ Soybeans } \\
\hline & & $\begin{array}{c}\text { Area } \\
\text { Planted } \\
\text { (ac) }\end{array}$ & $\begin{array}{c}\text { Tons } \\
\text { Harvested } \\
\text { (ton) }\end{array}$ & $\begin{array}{c}\text { Phosphorus } \\
\text { Applied } \\
\text { (ton yr }{ }^{-1} \text { ) }\end{array}$ & $\begin{array}{l}\text { Gray WF } \\
\left(m^{3} \text { ton }^{-1}\right)\end{array}$ & $\begin{array}{c}\text { Area } \\
\text { Planted } \\
\text { (ac) }\end{array}$ & $\begin{array}{c}\text { Tons } \\
\text { Harvested } \\
\text { (ton) }\end{array}$ & $\begin{array}{c}\text { Phosphorus } \\
\text { Applied } \\
\text { (ton } \mathrm{yr}^{-1} \text { ) }\end{array}$ & $\begin{array}{l}\text { Gray WF } \\
\left(m^{3} \operatorname{ton}^{-1}\right)\end{array}$ \\
\hline \multirow{8}{*}{ Michigan } & Berrien & 44,928 & 189,912 & 169 & 807 & 43,163 & 47,933 & 166 & 3,142 \\
\hline & Branch & 92,925 & 368,793 & 349 & 859 & 81,501 & 89,492 & 313 & 3,177 \\
\hline & Calhoun & 69,426 & 241,021 & 261 & 982 & 73,670 & 71,487 & 283 & 3,595 \\
\hline & Cass & 76,640 & 303,167 & 288 & 862 & 59,407 & 69,654 & 228 & 2,975 \\
\hline & Hillsdale & 67,520 & 268,203 & 254 & 858 & 91,124 & 96,616 & 350 & 3,290 \\
\hline & Kalamazoo & 50,140 & 193,190 & 188 & 885 & 36,566 & 44,503 & 141 & 2,866 \\
\hline & St. Joseph & 100,831 & 356,874 & 379 & 963 & 63,509 & 76,070 & 244 & 2,913 \\
\hline & Van Buren & 40,307 & 172,013 & 151 & 799 & 28,063 & 34,193 & 108 & 2,863 \\
\hline \multirow{7}{*}{ Indiana } & Dekalb & 40,291 & 172,321 & 261 & 1,372 & 73,525 & 88,942 & 398 & 4,064 \\
\hline & Elkhart & 54,209 & 247,378 & 351 & 1,286 & 45,614 & 61,161 & 247 & 3,666 \\
\hline & Kosciusko & 101,074 & 464,464 & 654 & 1,277 & 95,318 & 126,944 & 517 & 3,691 \\
\hline & LaGrange & 51,187 & 197,882 & 331 & 1,518 & 95,318 & 47,596 & 517 & 9,845 \\
\hline & Noble & 69,560 & 319,714 & 450 & 1,277 & 77,099 & 98,650 & 418 & 3,842 \\
\hline & St. Joseph & 65,435 & 311,390 & 423 & 1,233 & 53,398 & 68,810 & 289 & 3,815 \\
\hline & Steuben & 40,317 & 163,071 & 261 & 1,451 & 40,302 & 45,649 & 218 & 4,340 \\
\hline
\end{tabular}




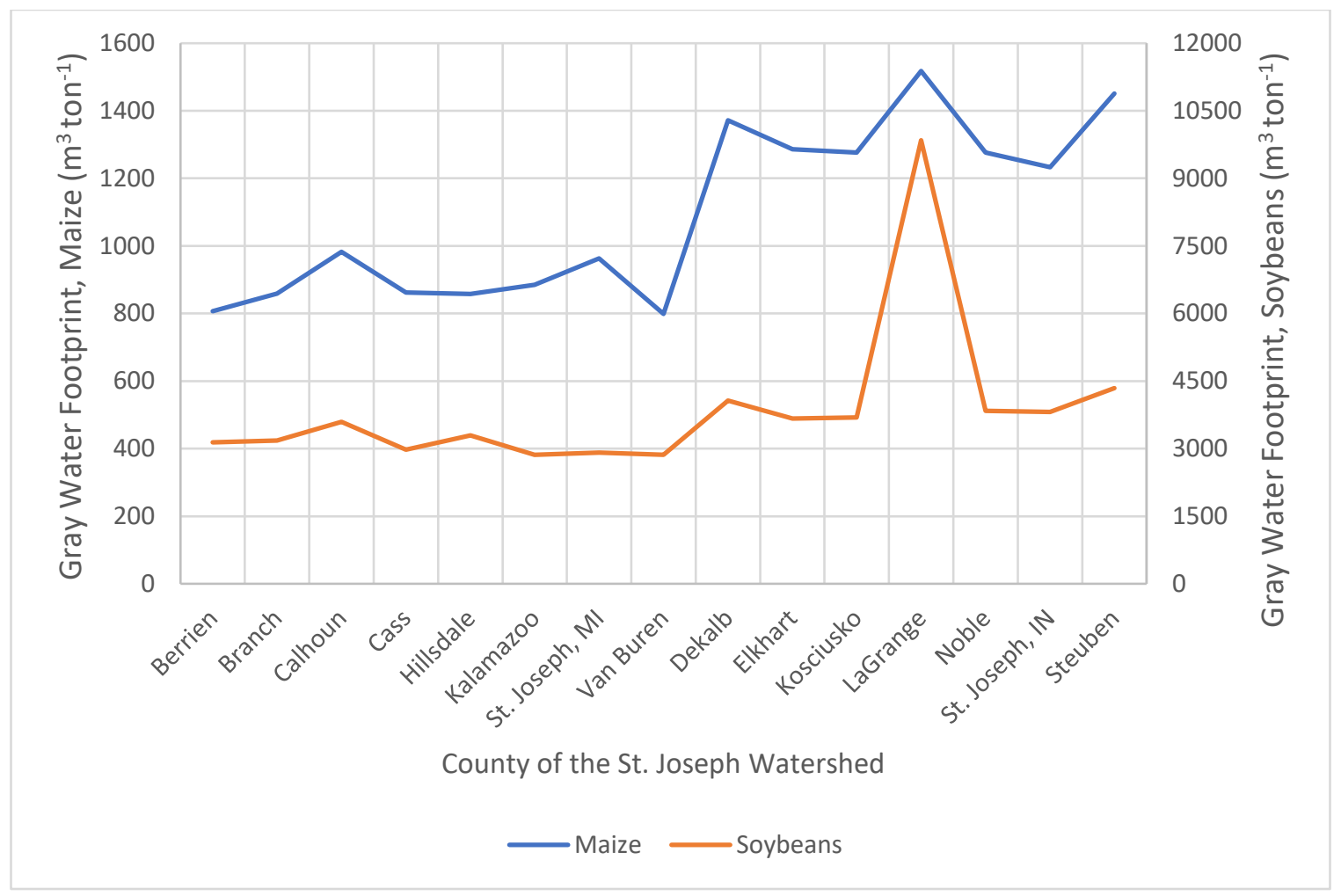

Figure 10. Gray water footprint for maize (blue, primary y-axis) and soybeans (orange, secondary y-axis) grown by county. 


\subsection{Traditional Total Water Footprint}

The total water footprint can be calculated using Equation 1 as the sum of the blue, green and gray water footprints. Figure 11 shows the total water footprint when considering the consumptive use of blue water resources for each of the simulated soil types. The result is consistent with the irrigation schedule chosen in this study: to ensure successful crop development and no reduction in seasonal yield, the land is being irrigated as needed. This means that if the soil is dry from a lack of rainfall (reduced green water footprint) then water is applied (increased blue water footprint), and the result is a balanced total water footprint. (This is not considering the instances in which irrigation occurs before a rain event and thus was unnecessary in hindsight, although accounting for blue water withdrawals would consider these instances.) Even though light soil types have the largest total water footprint for maize and soybeans, which aligns with the drainage characteristics that sandy soils exhibit, the differences among the results for each soil type were small. The reason for this is that the gray water footprint represents the largest footprint, while the blue water footprint generally offsets the green water footprint (Figure 12).

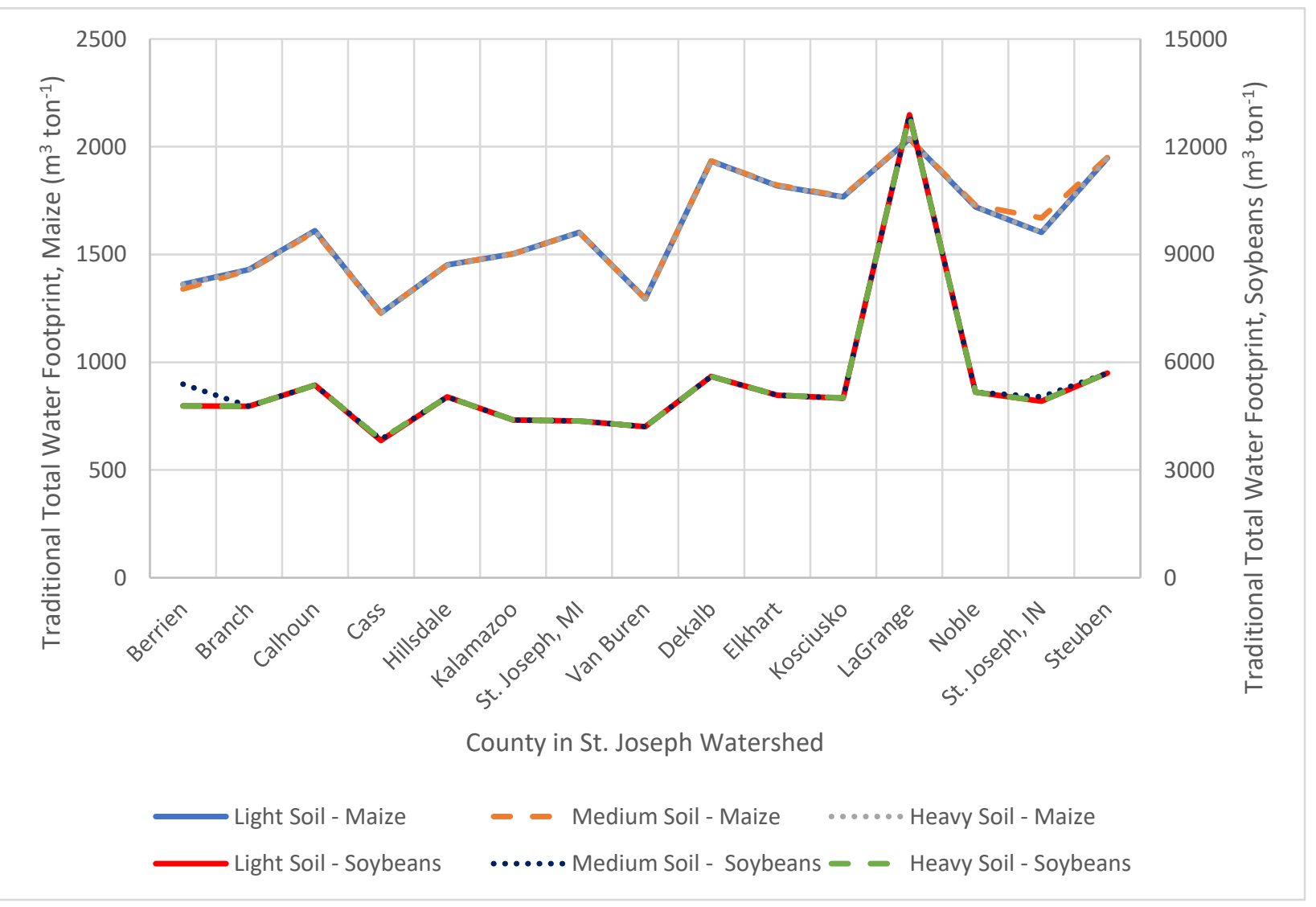

Figure 11. Traditional total water footprint for maize (primary y-axis) and soybeans (secondary y-axis) in St. Joseph watershed 

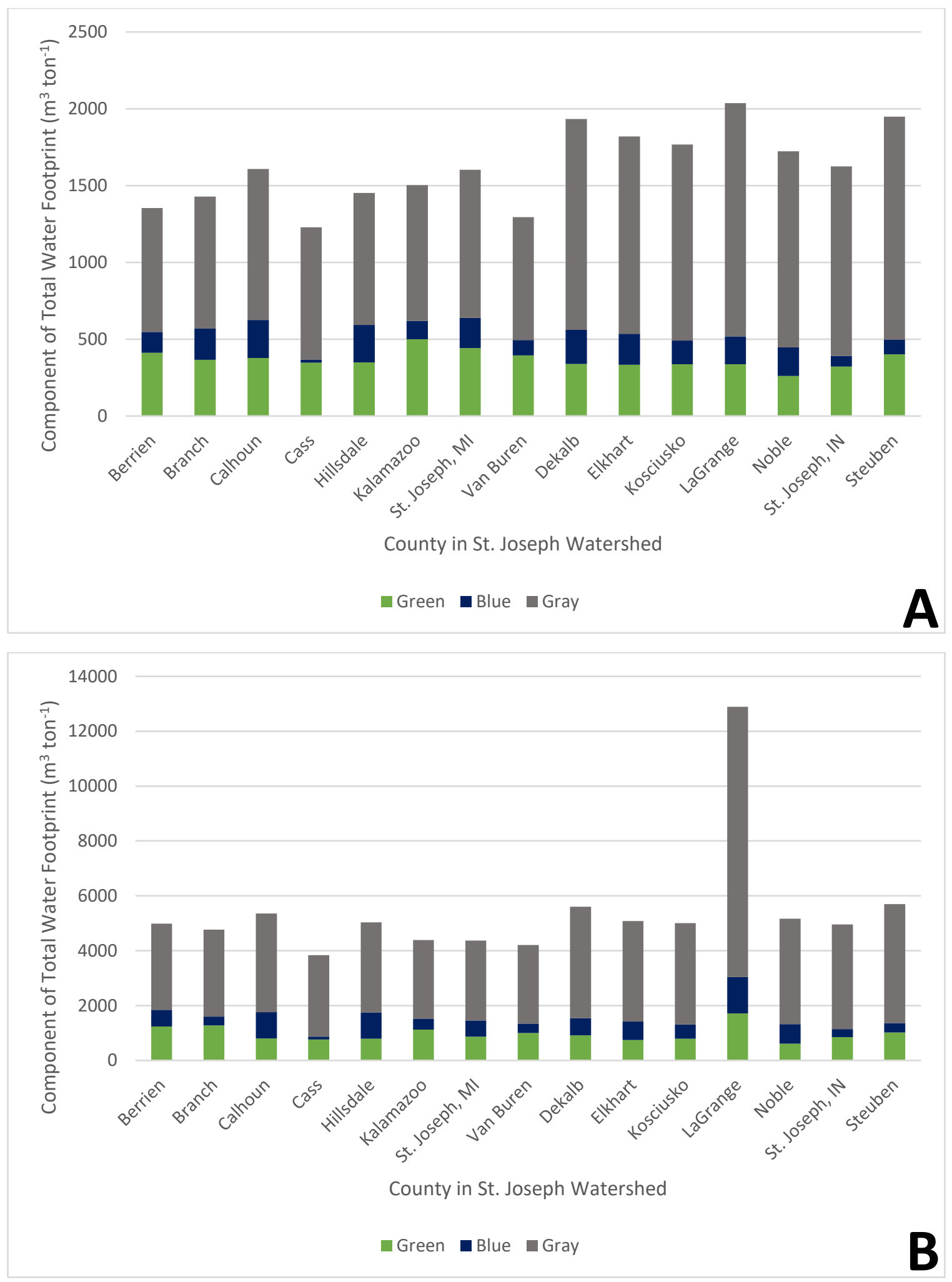

Figure 12. Contribution of each component of the total water footprint for maize (A) and soybeans (B). 


\subsection{Relative Total Water Footprint}

The relative total water footprint, as outlined in Equation 6, shows similar results to that of the traditional water footprint calculation, as would be expected since the baseline water footprint (for deciduous forests) includes only green water use and does not account for different soil types. Furthermore, since baseline ET rates from HAWQS and Hamilton et al. (2018) were similar, there is not a significant difference between the relative water footprint for each of the soil types simulated with the HAWQS ET rates (Figure 13) or with the Hamilton ET rate (Figure 14). Similar to what is seen in Figure 11, the results are nearly identical due to the large contribution of the gray water footprint. Considering only blue and green water use by the crops, Figure 15 compares the traditional and relative water footprints for maize and soybeans, indicating that by accounting for ET from a natural landscape, the relative water footprints of agricultural products may be significantly lower than calculated traditionally (Tables 1 and 2), at least in humid regions such as Great Lakes Basin.

Alternatively, Figure 15 shows that if the cultivated land in the St. Joseph watershed were allowed to return to deciduous forests (as modeled in HAWQS) or to woody vegetation species (as observed with the field study), the total water demands would be significantly reduced. Additionally, soybean cultivation requires more water resources than maize production. This is a concern since, as stated previously, Midwestern farms are increasing the intensity of soybean farming. However, if woody vegetation is incorporated into modern farming technique, the water demands would be reduced, as suggested in Figure 15. Though more analyses are needed to understand how other natural landscapes compare to agriculture water footprints, these results suggest that at least some inclusion of natural vegetation can help to make this water-intensive industry less deleterious on the freshwater resources of watersheds in the Great Lakes Basin. 


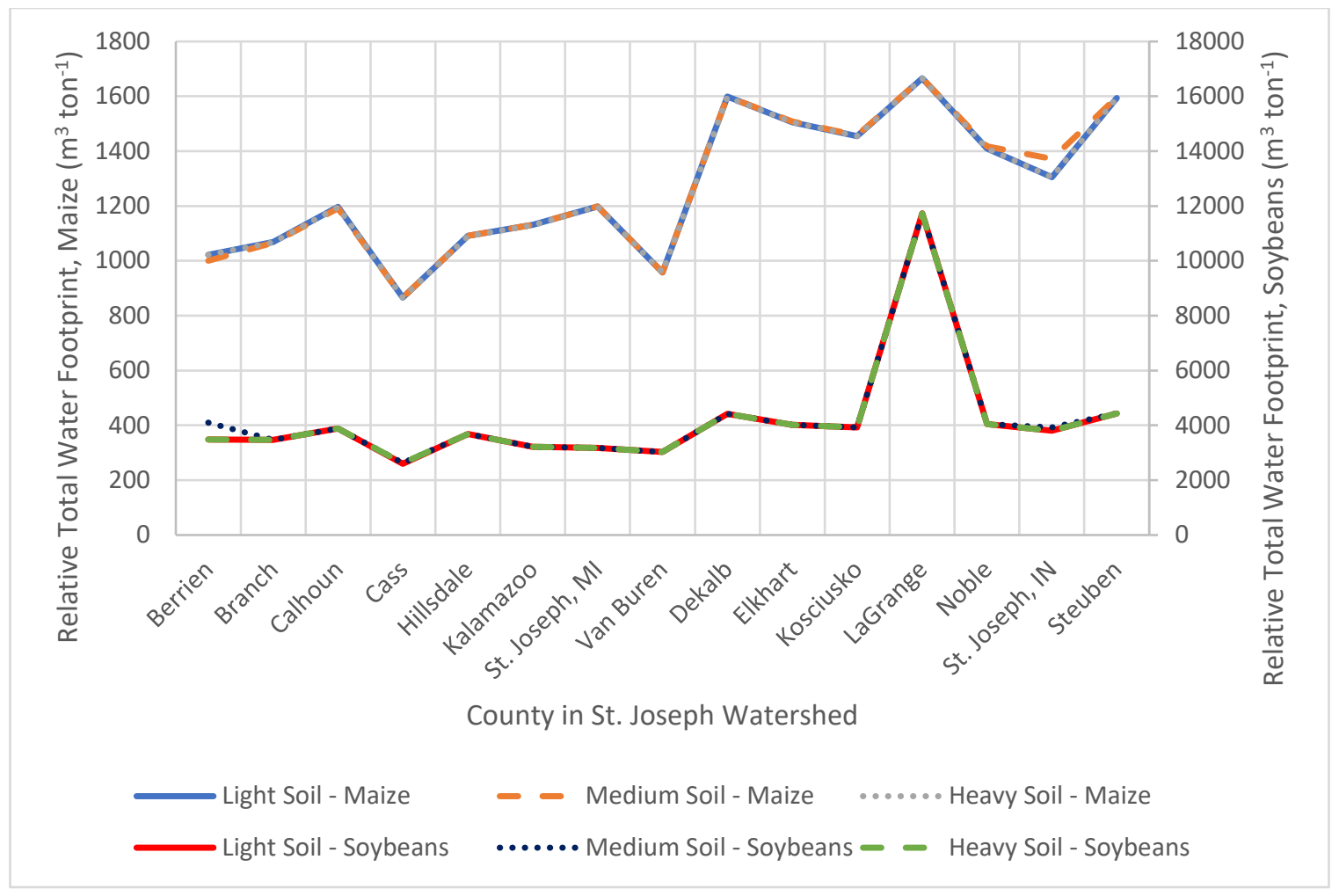

Figure 13. Relative water footprint as calculated using Equation 6 for maize (primary y-axis) and soybeans (secondary y-axis) with the baseline ET rates from HAWQS model.

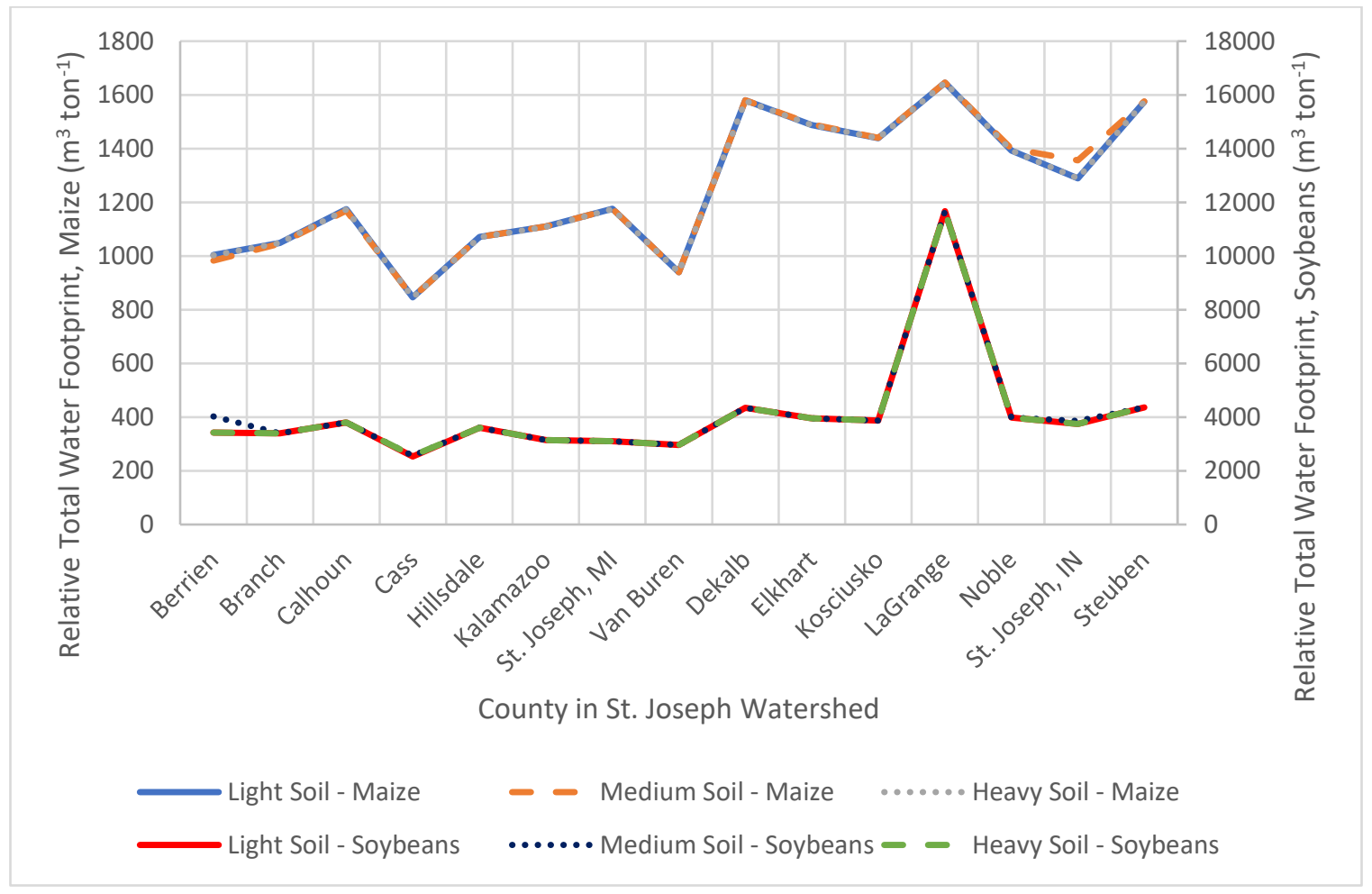

Figure 14. Relative water footprint as calculated using Equation 6 for maize (primary y-axis) and soybeans (secondary y-axis) with the baseline ET rates from the Hamilton et al. (2018) field study 


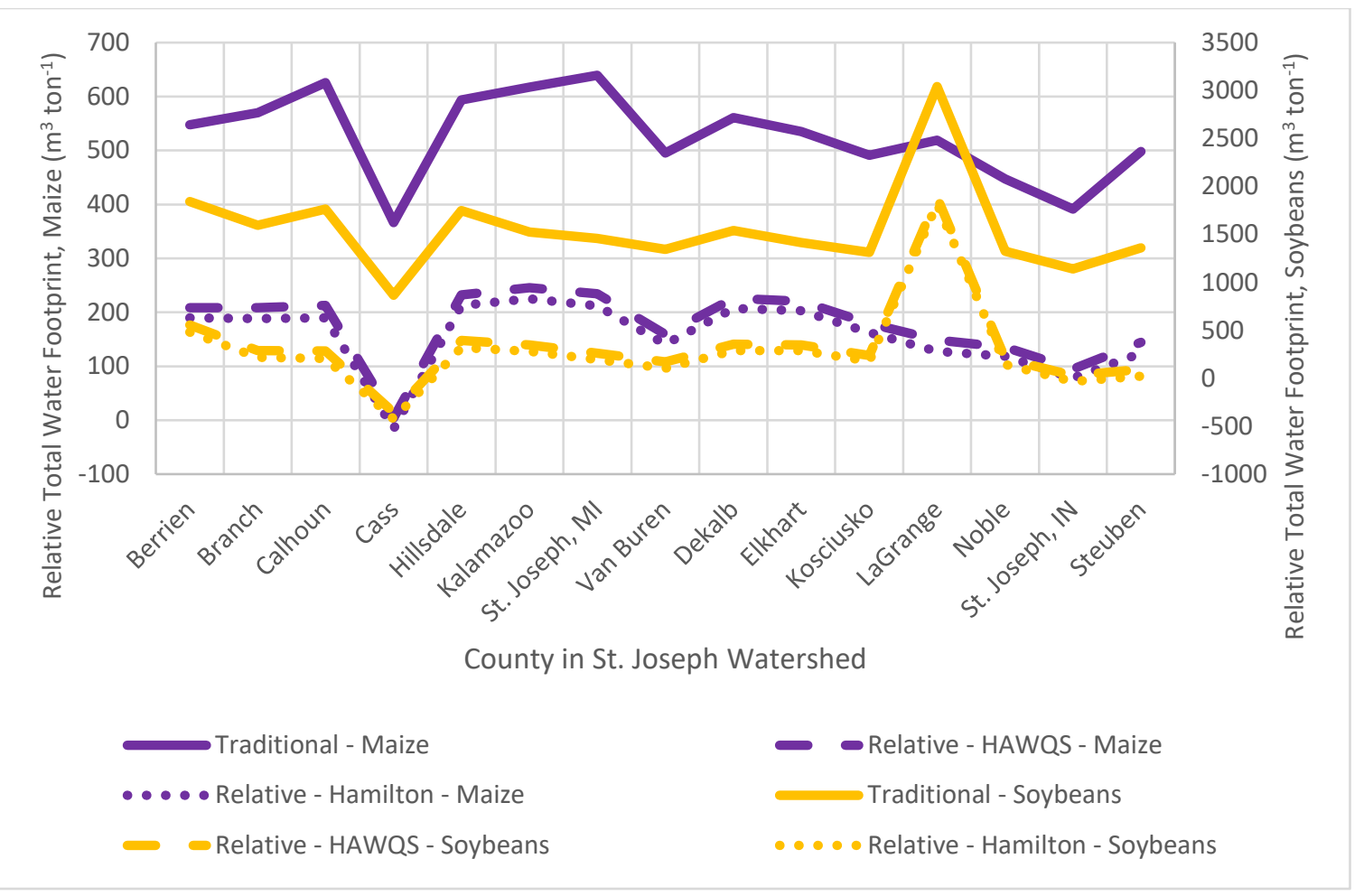

Figure 15. Relative total water footprint with gray water footprint component excluded for maize (primary y-axis) and soybeans (secondary y-axis) using both methods that quantify the baseline ET rates, represented as an average of all simulated soils.

\section{Conclusion}

The water footprint methodology has some important limitations - demand for many datasets that contain different types of information, limited examples of navigating data limitations, small-scale case studies, and lack of consideration of ecosystem impacts. This report addressed these limitations in several ways. First, focusing the analysis at the watershed-level provides a methodology for areas that may span more than one political border (such as multiple states, provinces, or counties) and for evaluating water use impacts at the landscape scale. Second, although data availability was still an issue in this study, examples of overcoming data limitations through the use of multiple datasets and application of agrohydrologic modeling have been given. For example, when the NOAA's CDO did not provide the necessary climatological data, specifically relative humidity, ISU's ASOS network provided what was lacking. Additionally, the green and blue ET rates and water use were calculated using FAO's CROPWAT. The results from the irrigation module with irrigation at critical depletion are considered to be the most reliable due to the inclusion of irrigation depths, which is realistic in the scope of agriculture. The rainfed schedule would be useful only if the desired analysis is to set the blue water footprint to zero (i.e., assuming no irrigation). Finally, the traditional water footprint equation does not contextualize the geographic and hydrologic water use patterns relative to a baseline (pre-development) or alternative land use scenario. The revision made to the total water footprint calculation accommodates such considerations by computing a relative water footprint. The baseline ET rates came from both a field study and a modeling study, with the results from HAWQS recommended for use assuming the model calibration is reliable and the natural landscape is represented by forests and perennial grasses. 
Recommended future work is based on the assumptions made throughout this study. Relative humidity data was compiled for every three days of each month at a specific reporting time (approximately noon) and then averaged. Future studies may be able to better approximate this information if CROPWAT or another agricultural production model is applied with daily or sub-daily time-steps. Wind speed was estimated from a map image and results were used for all counties, rather than based on a separate dataset for each county. Future work could further utilize ASOS since it has wind speed data available, though, like the humidity dataset, it is consuming to process. Daily rainfall data would also provide better insight into the day-to-day water balance of the watershed. In addition, using better methods for calculating the effective rain is a potential goal of future work, including the use of more detailed soil data. To better capture the soil variability across the watershed, the soils' total available moisture, maximum rain infiltration rate, and maximum rooting depth could be adjusted at the field scale based on available geospatial datasets such as STATSGO and SSURGO. Initial soil moisture depletion, which is weatherdependent, could be estimated from the HAWQS model. As outlined above, little to no change was observed in the crop ET values when adjustments were made to crop and soil characteristics in CROPWAT. This suggests the need for more research into the background calculations performed in CROPWAT, whether or not additional calibration is needed, and the feasibility of doing manual water budget and crop yield calculations at monthly and daily time-steps.

Regarding the water footprint calculations, the methodology followed for the green and blue was rather straightforward. However, there were many uncertainties involved with the gray water footprint. First, county-level application rates of fertilizers were not known, as only statewide averages for a limited number of fertilizers were accessible. Within this dataset, the year of this study's analysis - 2016 - was missing data for fertilizers applied to soybean-cultivated land; thus, 2017 data was used in its place. Another issue with the gray water footprint is a lack of data on leaching-runoff fractions. The assumption for this study of $\alpha=0.03$ was based on the gray water footprint manual (Franke et al., 2013). More data regarding this parameter is needed. The natural concentration of pollutants is also not readily available, so an assumed value of zero is often used, although this may be inappropriate depending on the study context. Additionally, this study did not consider the accumulation of phosphorus in the soils or concentration or dilution throughout the watershed as a result of the hydraulic processes in the stream network. A detailed SWAT model could be developed to include these considerations, assuming sufficient data is available. Additionally, the relative water footprint could further be improved if more than one type of natural vegetation were selected for the baseline ET rate, as there are many types of land cover available in HAWQS.

With the limitations of CROPWAT fully understood, future work may find other simulation programs to be better suited to the study context. The California Simulation of ET of Applied Water (Cal-SIMETAW; California Department of Water Resources, n.d.) estimates daily soil-water balances in order to determine the crop and applied water ET. Similar to CROPWAT, this model requires parameters that influence the crop-water balance such as climatological observations and crop coefficients. The Consumptive Use Program Plus (CUP+; California Department of Water Resources, n.d.) also estimates crop and applied water ET. This application, using climate, soil, and rainfall data, outputs the seasonal estimate of irrigation water requirements that are beneficial to informing irrigation planning and design. The HAWQS model, when used with defaulted parameters, is easy to use and may be valuable to future investigations. However, depending on the size of the watershed selected and HRUs included in the analysis, the user will need to devote a considerable amount of time to processing and organizing the results. 


\section{References}

Aldaya, M. M., Allan, J. A. and Hoekstra, A. Y. (2010) 'Strategic importance of green water in international crop trade', Ecological Economics, vol 69, no 4, pp887-894

Allen, R. G., Pereira, L. S., Raes, D. and Smith, M. (1998) 'Crop ET: Guidelines for computing crop water requirements', FAO Irrigation and Drainage Paper 56, Food and Agriculture Organization, Rome

Arnold, J.G., Kiniry, J.R., Srinibasan, R., Williams, J.R., Haney, E.B., Neitsch, S.L. (2012), 'SWAT Input/Output Documentation File, Version 2012', Texas Water Resource Institute, Accessed May $1^{\text {st }}, 2021$, from https://swat.tamu.edu/docs/

ASOS (Automated Surface Observing System) (2001) 'ASOS-AWOS-METAR Data Download', Accessed January $1^{\text {st }}, 2020$, from https://mesonet.agron.iastate.edu/ASOS/

Baker, R.D., Ball, S.T., Flynn, R. (2002), 'Soil Analysis: a key to soil nutrient management', New Mexico State University College of Agricultural, Consumer and Environmental sciences, Guide A-137, Accessed July $21^{\text {st }} 2021$ from https://aces.nmsu.edu/pubs/ a/A137/

California Department of Water Resources (n.d.) 'Agricultural Water Use Models', Land \& Water Use, Accessed May $1^{\text {st }} 2019$ from https://water.ca.gov/Programs/Water-Use-And-Efficiency/Land-And-WaterUse/Agricultural-Water-Use-Models

Chapagain, A. K. and Hoekstra, A. Y. (2003) 'Virtual water flows between nations in relation to trade in livestock and livestock products', Value of Water Research Report Series No.13, UNESCO-IHE, Delft, Netherlands, www.waterfootprint.org/Reports/Report13.pdf

Chapagain, A. K., and Hoekstra, A. Y. (2007) 'The water footprint of coffee and tea consumption in the Netherlands', Ecological Economics, vol 64, no 1, pp109-118

Chapagain, A. K. and Hoekstra, A. Y. (2010) 'The green, blue and grey water footprint of rice from both a production and consumption perspective', Value of Water Research Report Series No.40, UNESCO-IHE, Delft, Netherlands, www.waterfootprint.org/Reports/Report40-WaterFootprintRice.pdf

Dagdelen N, Yilmaz E, Sezgin F, Gurbuz T (2005). 'Water yield relation and water use efficiency of cotton (Gossypium hirsutum I.) and second crop corn (Zea mays I.) in western Turkey'. Agricultural Water Management, vol 82, pp 63-85

Dehghanisanij, H. et al (2009), 'Assessment of wheat and maize water productivities and production function for cropping system decisions in arid and semiarid regions', Irrigation and Drainage, vol 58, pp 105-115.

EPA (Environmental Protection Agency) (2017). 'Great Lakes Facts and Figures ' Accesssed August $5^{\text {th }}, 2021$ from https://www.epa.gov/greatlakes/great-lakes-facts-and-figures

ERS (Economic Research Service) (2019). 'Fertilizer Use and Price', Accessed July 18 ${ }^{\text {th }}, 2021$ from USDA ERS - Fertilizer Use and Price

Franke, N.A., Boyacioglu, H., Hoekstra, A.Y. (2013) 'Grey Water Footprint Accounting: Tier 1 Supporting Guidelines', Value of Water: Research Report Series No. 65, UNESCO-IHE, Delft, Netherlands, https://waterfootprint.org/en/resources/publications/value-water-research-report-series-unesco-ihe/ 
Foxx, T.S., Tierney, G.D., Williams, J.M. (1984) 'Rooting Depths of Plants Relative to Biological and Environmental Factors', Los Alamos National Laboratory, New Mexico, United States, https://inis.iaea.org/collection/NCLCollectionStore/ Public/16/061/16061888.pdf

The Friends of the St. Joe River Association (2009) 'St. Joseph River Watershed Planning Project: Final Project Report', Accessed March 1 ${ }^{\text {st }}, 2021$ from http://www.stjoeriver.net/index.htm

Hamilton, S.K, Hussain, M.Z., Lowrie, C., Basso, B., Roberston, G.P. (2018) 'ET is resilient in the face of land cover and climate change in a humid temperature catchment', Hydrological Process, volume 32, pp 655663.

HAWQS (Hydrologic and Water Quality System) (2019). 'HAWQS User Guide Version 1.1', Spatial Sciences Laboratory Texas A \& M AgriLife Research College Station, Texas. Accessed May $1^{\text {st }} 2021$ from https://hawqs.tamu.edu/\#/help

Heridari, A., Mayer, A., Watkins, D. (2019) 'Hydrologic impacts and trade-offs associated with forest-based bioenergy development practices in snow-dominated watershed, Wisconsin, USA', Journal of Hydrology, vol 574, pp 421-429.

Heridari, A., Mayer, A., Watkins, D., Castillo, M. M. (2020), 'Hydrologic impacts and trade-offs associated with developing oil palm for bioenergy in Tabasco, Mexico', Journal of Hydrology: Regional Studies, vol 31.

Hoekstra, A. Y. (ed) (2003) 'Virtual water trade: Proceedings of the International Expert Meeting on Virtual Water Trade', 12-13 December 2002, Value of Water Research Report Series No 12, UNESCO-IHE, Delft, Netherlands, www.waterfootprint.org/Reports/Report12.pdf

Hoekstra, A. Y. and Mekonnen, M. (2020) 'Water Footprint Assessment Tool'. Accessed March 1 ${ }^{\text {st }}, 2021$ from https://www.waterfootprintassessmenttool.org/world/scope\#

Kipkorir, E.C., Raes, D., Massawe, B. (2002) 'Seasonal water production functions and yield response factors for maize and onion in Perkerra, Kenya', Agricultural Water Management, vol 56, pp 229-240

Matousek, J. (2010) 'St. Joseph River Watershed Report', Michigan Department of Environment, Great Lakes, and Energy, Accessed April 20 ${ }^{\text {th }}, 2021$ from https://www.michigan.gov/documents/egle/egle-wrdswas-st.joseph watershed 2020682142 7.pdf

MDEQ (Michigan Department of Environmental Quality) (2010), 'Phosphorus limits and implementation in Michigan', Accessed July 21 2021 from https://www.michigan.gov/documents/deq/wrd-swasnutrients-npdeslimits 366813 7.pdf

MLRC (Multi-Resolution Land Characteristics) (2016), 'Land Cover', Accessed May $1^{\text {st }}, 2019$, from https://www.mrlc.gov/data

NASS (National Agricultural Statistics Service) (2010) 'Usual Planting and Harvesting Dates for U.S. Field Crops' Accessed May $1^{\text {st }} 2019$ from https://usda.library.cornell.edu/concern/publications/vm40xr56k

NASS (2016), 'CropScape - Cropland Data Layers', Accessed May $1^{\text {st }} 2019$ from https://nassgeodata.gmu.edu/CropScape/ 
Neitsch, S. L., Arnold, J. G., Kiniry, J. R., \& Williams, J. R. (2011). Soil and water assessment tool theoretical documentation version 2009. Texas Water Resources Institute.

NOAA (National Oceanic and Atmospheric Administration) (n.d., A), 'National Centers for Environmental Information (NCEI) Climate Data online (CDO) Global Summary of the Month' Accessed May 1 ${ }^{\text {st }}, 2019$ from https://www.ncdc.noaa.gov/cdo-web/search

NOAA (National Oceanic and Atmospheric Administration) (n.d., B), 'Societal Impacts: U.S. Wind Climatology' Accessed May 1 ${ }^{\text {st }}, 2019$ from https://www.ncdc.noaa.gov/societal-impacts/wind/

NRCS (National Resource Conservation Service) (2020A), 'USA Soils Hydrologic Group', Accessed September 2019 from https://landscape11.arcgis.com/arcgis/services/USA Soils Hydrologic Group/ImageServer

NRCS (National Resource Conservation Service) (2020B), 'USA Soils Drainage Class', Accessed September 2019 from https://landscape11.arcgis.com/arcgis/services/USA Soils Drainage Class/ImageServer

Oktem, A. (2008). 'Effect of water shortage on yield, and protein and mineral compositions of dripirrigated sweet corn in sustainable agricultural ecosystems', Agricultural Water Management, vol 95, pp 1103-1010.

Ridoutt, B. G., Juliano, P., Sanguansri, P. and Sellahewa, J. (2010) 'The water footprint of food waste: Case study of fresh mango in Australia', Journal of Cleaner Production, vol 18, no. 16-17, pp1714-1721

University of Minnesota (2018) 'Understanding phosphorus fertilizers', University of Minnesota Extension, Accessed July $21^{\text {st }} 2021$ from https://extension.umn.edu/phosphorus-and-potassium/understandingphosphorus-fertilizers\#available-619562

USDA (U.S. Department of Agriculture) (2019) 'Census of Agriculture for 2017', Table 24: Selected Crops Harvested for 2017, Accessed May $1^{\text {st }} 2019$ from https://www.nass.usda.gov/Publications/AgCensus/2017/index.php

Van Oel, P. R. and Hoekstra, A. Y. (2010) 'The green and blue water footprint of paper products: Methodological considerations and quantification', Value of Water Research Report Series No 46, UNESCO-IHE, Delft, Netherlands, www.waterfootprint.org/Reports/Report46-WaterFootprintPaper 


\section{A. Supplementary Information - Datasets}

Table A. 1 Temperature data for each month of 2016 for the St. Joseph Watershed

\begin{tabular}{|c|c|c|c|c|c|c|c|c|c|c|c|c|c|}
\hline State & County & Jan & Feb & Mar & Apr & May & Jun & Jul & Aug & Sep & Oct & Nov & Dec \\
\hline \multirow{8}{*}{ Michigan } & Berrien & 25.9 & 31.6 & 44.4 & 49.4 & 59.8 & 70.9 & 73.7 & 74.6 & 69 & 57.5 & 46.9 & 28.2 \\
\hline & Branch & 26 & 28.7 & 41.9 & 47.2 & 58.7 & 68.4 & 72.3 & 72.8 & 66.8 & 54.6 & 45.2 & 26.4 \\
\hline & Calhoun & 26.3 & 29.3 & 43.1 & 47.2 & 59.3 & 68.4 & 72.9 & 72.7 & 66.2 & 56.5 & 45.6 & 27.3 \\
\hline & Cass & 23.7 & 27.9 & 40.4 & 47.9 & 57.1 & 68.4 & 71 & 73.1 & 67.3 & 55.7 & 44.8 & 26.7 \\
\hline & Hillsdale & 23.4 & 28.7 & 40.2 & 45.6 & 57.2 & 68.1 & 72.4 & 72.8 & 65.7 & 54.2 & 43.9 & 25.8 \\
\hline & Kalamazoo & 26.5 & 29.4 & 42.2 & 47.9 & 59.4 & 69.4 & 73.8 & 73.8 & 67.5 & 55.8 & 45.5 & 27.6 \\
\hline & St. Joseph & 24.4 & 29.1 & 41.3 & 46.9 & 57.5 & 68 & 72.1 & 73 & 67.9 & 54.8 & 44.4 & 26.4 \\
\hline & Van Buren & 24.9 & 28.5 & 39.7 & 45.1 & 57.2 & 67.1 & 72.2 & 72.8 & 66.6 & 54.8 & 44.4 & 26.9 \\
\hline \multirow{7}{*}{ Indiana } & DeKalb & 25.1 & 31.1 & 44.5 & 48.4 & 59.4 & 69.4 & 72.5 & 72.9 & 67.1 & 56.7 & 45.6 & 25.7 \\
\hline & Elkhart & 24.9 & 29.7 & 43.5 & 48.7 & 60.1 & 71.5 & 74.2 & 75.1 & 68.7 & 57.2 & 46.2 & 25.3 \\
\hline & Kosciusko & 25.7 & 30.3 & 43.6 & 48.4 & 59.7 & 70.1 & 73.6 & 74.6 & 68.2 & 56.7 & 46.5 & 25.8 \\
\hline & LaGrange & 25 & 29.4 & 42.9 & 47.4 & 58.5 & 69.1 & 72.6 & 73.4 & 67.1 & 55.3 & 44.9 & 25.8 \\
\hline & Noble & 25.1 & 30.1 & 43.9 & 48 & 59.1 & 69.7 & 73 & 74.7 & 63 & 67.8 & 72.4 & 71.9 \\
\hline & St. Joseph & 24.8 & 29.1 & 42.6 & 47.6 & 58.4 & 69.4 & 73.1 & 74.2 & 67.9 & 55.8 & 45.9 & 25.5 \\
\hline & Steuben & 24.6 & 30 & 45 & 46.9 & 57.6 & 68.6 & 71.9 & 72.7 & 66.5 & 54.6 & 43.6 & 25.1 \\
\hline
\end{tabular}

Table A. 2 Average humidity for each month of 2016, for each county of the St. Joseph watershed

\begin{tabular}{|c|c|c|c|c|c|c|c|c|c|c|c|c|c|}
\hline State & County & Jan & Feb & Mar & Apr & May & Jun & Jul & Aug & Sep & Oct & Nov & Dec \\
\hline \multirow{8}{*}{ Michigan } & Berrien & 72 & 67 & 64 & 63 & 59 & 58 & 59 & 64 & 59 & 66 & 64 & 63 \\
\hline & Branch & 74 & 71 & 68 & 66 & 58 & 51 & 65 & 64 & 53 & 61 & 68 & 71 \\
\hline & Calhoun & 70 & 68 & 69 & 63 & 58 & 57 & 65 & 72 & 62 & 63 & 71 & 72 \\
\hline & Cass & 74 & 73 & 71 & 68 & 64 & 62 & 66 & 69 & 67 & 71 & 69 & 70 \\
\hline & Hillsdale & 73 & 74 & 73 & 68 & 51 & 43 & 56 & 63 & 55 & 59 & 64 & 75 \\
\hline & Kalamazoo & 69 & 68 & 64 & 61 & 56 & 53 & 56 & 61 & 57 & 61 & 66 & 65 \\
\hline & St. Joseph & 72 & 73 & 69 & 66 & 60 & 61 & 60 & 60 & 64 & 68 & 65 & 72 \\
\hline & Van Buren & 72 & 70 & 71 & 66 & 63 & 64 & 66 & 70 & 65 & 69 & 72 & 68 \\
\hline \multirow{7}{*}{ Indiana } & DeKalb & 67 & 66 & 68 & 65 & 58 & 54 & 54 & 56 & 55 & 58 & 66 & 69 \\
\hline & Elkhart & 70 & 73 & 68 & 65 & 57 & 52 & 55 & 59 & 55 & 60 & 65 & 65 \\
\hline & Kosciusko & 74 & 72 & 70 & 67 & 58 & 60 & 65 & 66 & 60 & 56 & 66 & 67 \\
\hline & LaGrange & 84 & 89 & 84 & 86 & 82 & 76 & 81 & 68 & 65 & 67 & 69 & 71 \\
\hline & Noble & 73 & 73 & 71 & 68 & 962 & 60 & 65 & 83 & 92 & 94 & 90 & 84 \\
\hline & St. Joseph & 83 & 83 & 85 & 79 & 79 & 72 & 89 & 91 & 93 & 92 & 79 & 81 \\
\hline & Steuben & 74 & 79 & 74 & 72 & 68 & 72 & 78 & 69 & 67 & 67 & 62 & 69 \\
\hline
\end{tabular}


Table A. 3 Monthly totals of precipitation for each county

\begin{tabular}{|c|c|c|c|c|c|c|c|c|c|c|c|c|c|}
\hline State & County & Jan & Feb & Mar & Apr & May & Jun & Jul & Aug & Sep & Oct & Nov & Dec \\
\hline \multirow{8}{*}{ Michigan } & Berrien & 2.06 & 1.94 & 3.49 & 3.65 & 3.09 & 5.59 & 2.53 & 13.29 & 2.47 & 4.61 & 2.26 & 2.61 \\
\hline & Branch & 1.06 & 1.45 & 2.76 & 3.54 & 2.13 & 3.28 & 6.66 & 0.48 & 3.27 & 3.41 & 2.24 & 1.94 \\
\hline & Calhoun & 1.54 & 1.7 & 4.44 & 2.72 & 4.23 & 0.82 & 3.72 & 7.1 & 3.7 & 3.04 & 1.87 & 2.59 \\
\hline & Cass & 2.13 & 2.58 & 3.63 & 3.7 & 4.12 & 2.28 & 2.78 & 11.73 & 3.08 & 4.01 & 2.9 & 2.18 \\
\hline & Hillsdale & 1.85 & 1.61 & 3.27 & 3.78 & 2.54 & 2.22 & 0.09 & 6.17 & 3.11 & 4.93 & 3.03 & 2.05 \\
\hline & Kalamazoo & 0.89 & 0.69 & 2.97 & 3.13 & 3.34 & 1.9 & 7.47 & 7.38 & 3.33 & 3.36 & 2.07 & 1.43 \\
\hline & St. Joseph & 1.39 & 1.46 & 3.22 & 3.27 & 3.33 & 3.31 & 3.3 & 10.63 & 4.86 & 3.11 & 2.89 & 2.15 \\
\hline & Van Buren & 2.26 & 3.01 & 3.2 & 2.89 & 4.09 & 2.66 & 5.28 & 8.37 & 2.49 & 3.66 & 2.48 & 3.64 \\
\hline \multirow{7}{*}{ Indiana } & DeKalb & 1.36 & 1.44 & 3.12 & 2.96 & 3.43 & 4.96 & 2.58 & 3.42 & 3.38 & 3.04 & 3.83 & 2.22 \\
\hline & Elkhart & 1.67 & 1.83 & 3.21 & 3.22 & 2.74 & 4.37 & 2.19 & 6.24 & 3.78 & 4.39 & 3.17 & 2.16 \\
\hline & Kosciusko & 1.48 & 1.64 & 4.07 & 3.42 & 2.17 & 4.01 & 2.91 & 5.31 & 3.44 & 3.64 & 4.11 & 1.79 \\
\hline & LaGrange & 1.13 & 1.29 & 2.44 & 3.03 & 3.17 & 2.67 & 1.96 & 5.13 & 3.16 & 3.66 & 2.13 & 1.68 \\
\hline & Noble & 1.24 & 1.53 & 3.26 & 3.2 & 3.28 & 2.62 & 1.79 & 4.52 & 4.07 & 3.21 & 4.68 & 2.11 \\
\hline & St. Joseph & 1.61 & 2.19 & 4.17 & 4.67 & 2.5 & 3.26 & 3.25 & 12.81 & 3.74 & 3.48 & 2.98 & 2 \\
\hline & Steuben & 1.28 & 1.91 & 3.24 & 4.07 & 2.84 & 5.11 & 3.79 & 4.3 & 2.29 & 3.29 & 2.47 & 2.32 \\
\hline
\end{tabular}

Table A. 4 Latitude coordinates, in degree North and radians, for each county.

\begin{tabular}{|cccc}
\hline \multirow{3}{*}{ State } & County & Latitude $(\mathbf{\circ} \mathbf{N})$ & Latitude (radians) \\
\hline \multirow{4}{*}{ Michigan } & Berrien & 41.84 & 0.73 \\
& Branch & 41.96 & 0.73 \\
& Calhoun & 42.37 & 0.74 \\
& Cass & 41.99 & 0.73 \\
& Hillsdale & 41.94 & 0.73 \\
& Kalamazoo & 42.23 & 0.74 \\
& St. Joseph & 41.93 & 0.73 \\
& Van Buren & 42.38 & 0.74 \\
& DeKalb & 41.34 & 0.72 \\
& Elkhart & 41.56 & 0.73 \\
& Kosciusko & 41.36 & 0.72 \\
& LaGrange & 41.94 & 0.73 \\
& Noble & 41.47 & 0.72 \\
& St. Joseph & 41.71 & 0.73 \\
& Steuben & 41.66 & 0.73
\end{tabular}


Table A. 5 Calculations for sunset hour angle and hours of sunlight for each county of the watershed

\begin{tabular}{|c|c|c|c|c|c|c|c|c|c|c|c|c|}
\hline Month & Jan & $\mathrm{Feb}$ & Mar & $A p r$ & May & Jun & Jul & Aug & Sep & Oct & Nov & Dec \\
\hline J & 15 & 46 & 75 & 106 & 136 & 167 & 197 & 228 & 259 & 289 & 320 & 350 \\
\hline $\begin{array}{c}\text { Solar } \\
\text { Declination, } \delta\end{array}$ & -0.37 & -0.23 & -0.04 & 0.17 & 0.33 & 0.41 & 0.37 & 0.24 & 0.03 & -0.17 & -0.34 & -0.41 \\
\hline County & \multicolumn{12}{|c|}{ Sunset hour angle } \\
\hline Berrien & 1.22 & 1.36 & 1.53 & 1.73 & 1.88 & 1.97 & 1.93 & 1.79 & 1.6 & 1.42 & 1.25 & 1.17 \\
\hline Branch & 1.21 & 1.36 & 1.53 & 1.73 & 1.89 & 1.97 & 1.93 & 1.79 & 1.6 & 1.42 & 1.25 & 1.17 \\
\hline Calhoun & 1.21 & 1.35 & 1.53 & 1.73 & 1.89 & 1.98 & 1.94 & 1.79 & 1.6 & 1.41 & 1.25 & 1.17 \\
\hline Cass & 1.21 & 1.36 & 1.53 & 1.73 & 1.89 & 1.97 & 1.93 & 1.79 & 1.6 & 1.42 & 1.25 & 1.17 \\
\hline Hillsdale & 1.21 & 1.36 & 1.53 & 1.73 & 1.89 & 1.97 & 1.93 & 1.79 & 1.6 & 1.42 & 1.25 & 1.17 \\
\hline Kalamazoo & 1.21 & 1.36 & 1.53 & 1.73 & 1.89 & 1.97 & 1.93 & 1.79 & 1.6 & 1.41 & 1.25 & 1.17 \\
\hline St. Joseph & 1.21 & 1.36 & 1.53 & 1.73 & 1.89 & 1.97 & 1.93 & 1.79 & 1.6 & 1.42 & 1.25 & 1.17 \\
\hline Van Buren & 1.21 & 1.35 & 1.53 & 1.73 & 1.89 & 1.98 & 1.94 & 1.79 & 1.6 & 1.41 & 1.25 & 1.17 \\
\hline DeKalb & 1.22 & 1.36 & 1.53 & 1.72 & 1.88 & 1.96 & 1.92 & 1.78 & 1.6 & 1.42 & 1.26 & 1.18 \\
\hline Elkhart & 1.22 & 1.36 & 1.53 & 1.72 & 1.88 & 1.96 & 1.93 & 1.79 & 1.6 & 1.42 & 1.26 & 1.18 \\
\hline Kosciusko & 1.22 & 1.36 & 1.53 & 1.72 & 1.88 & 1.96 & 1.92 & 1.78 & 1.6 & 1.42 & 1.26 & 1.18 \\
\hline LaGrange & 1.21 & 1.36 & 1.53 & 1.73 & 1.89 & 1.97 & 1.93 & 1.79 & 1.6 & 1.42 & 1.25 & 1.17 \\
\hline Noble & 1.22 & 1.36 & 1.53 & 1.72 & 1.88 & 1.96 & 1.92 & 1.79 & 1.6 & 1.42 & 1.26 & 1.18 \\
\hline St. Joseph & 1.22 & 1.36 & 1.53 & 1.72 & 1.88 & 1.97 & 1.93 & 1.79 & 1.6 & 1.42 & 1.25 & 1.18 \\
\hline Steuben & 1.22 & 1.36 & 1.53 & 1.72 & 1.88 & 1.96 & 1.93 & 1.79 & 1.6 & 1.42 & 1.26 & 1.18 \\
\hline County & \multicolumn{12}{|c|}{ Hours of Sunlight, $\mathbf{N}$} \\
\hline Berrien & 9.3 & 10.4 & 11.7 & 13.2 & 14.4 & 15 & 14.7 & 13.7 & 12.2 & 10.8 & 9.6 & 9 \\
\hline Branch & 9.3 & 10.4 & 11.7 & 13.2 & 14.4 & 15 & 14.7 & 13.7 & 12.2 & 10.8 & 9.6 & 9 \\
\hline Calhoun & 9.2 & 10.3 & 11.7 & 13.2 & 14.4 & 15.1 & 14.8 & 13.7 & 12.2 & 10.8 & 9.5 & 8.9 \\
\hline Cass & 9.3 & 10.4 & 11.7 & 13.2 & 14.4 & 15 & 14.8 & 13.7 & 12.2 & 10.8 & 9.6 & 9 \\
\hline Hillsdale & 9.3 & 10.4 & 11.7 & 13.2 & 14.4 & 15 & 14.7 & 13.7 & 12.2 & 10.8 & 9.6 & 9 \\
\hline Kalamazoo & 9.2 & 10.4 & 11.7 & 13.2 & 14.4 & 15.1 & 14.8 & 13.7 & 12.2 & 10.8 & 9.5 & 8.9 \\
\hline St. Joseph & 9.3 & 10.4 & 11.7 & 13.2 & 14.4 & 15 & 14.7 & 13.7 & 12.2 & 10.8 & 9.6 & 9 \\
\hline Van Buren & 9.2 & 10.3 & 11.7 & 13.2 & 14.4 & 15.1 & 14.8 & 13.7 & 12.2 & 10.8 & 9.5 & 8.9 \\
\hline DeKalb & 9.3 & 10.4 & 11.7 & 13.2 & 14.3 & 15 & 14.7 & 13.6 & 12.2 & 10.8 & 9.6 & 9 \\
\hline Elkhart & 9.3 & 10.4 & 11.7 & 13.2 & 14.4 & 15 & 14.7 & 13.6 & 12.2 & 10.8 & 9.6 & 9 \\
\hline Kosciusko & 9.3 & 10.4 & 11.7 & 13.2 & 14.4 & 15 & 14.7 & 13.6 & 12.2 & 10.8 & 9.6 & 9 \\
\hline LaGrange & 9.3 & 10.4 & 11.7 & 13.2 & 14.4 & 15 & 14.7 & 13.7 & 12.2 & 10.8 & 9.6 & 9 \\
\hline Noble & 9.3 & 10.4 & 11.7 & 13.2 & 14.4 & 15 & 14.7 & 13.6 & 12.2 & 10.8 & 9.6 & 9 \\
\hline St. Joseph & 9.3 & 10.4 & 11.7 & 13.2 & 14.4 & 15 & 14.7 & 13.7 & 12.2 & 10.8 & 9.6 & 9 \\
\hline Steuben & 9.3 & 10.4 & 11.7 & 13.2 & 14.4 & 15 & 14.7 & 13.7 & 12.2 & 10.8 & 9.6 & 9 \\
\hline
\end{tabular}




\section{B. Supplementary Information - CWR Module}

CWR is the amount of water that is needed to adequately supply crops with water throughout the growing season and is the difference between crop ET $\left(E T_{c}\right)$ and the effective rain $\left(P_{e f f}\right)$. This module outputs the $\mathrm{ET}_{\mathrm{c}}\left(\mathrm{mm}\right.$ day $\left.{ }^{-1}\right)$, the effective rain $\left(\mathrm{mm} \mathrm{dec}^{-1}\right.$ and $\left.\mathrm{mm} \mathrm{day}^{-1}\right)$, and the irrigation requirement $\left(\mathrm{mm} \mathrm{dec}^{-1}\right)$, where the unit "dec" represents a 10-day period. The irrigation requirement provides a volume of water needed when there is not sufficient rainfall to account for the water lost from ET. There are many of the crop-specific values that include some dependence on the soil texture and composition: crop coefficient $\mathrm{K}_{\mathrm{c}}$, rooting depth, critical depletion fraction $\mathrm{p}$, and yield response factor $\mathrm{K}_{\mathrm{y}}$. Thus, an analysis was conducted to test the changes that the CWR might output upon manipulation of these variables.

$K_{c}$ integrates the influence that the climate and soil ET have on crop development. But, because of the minimal effect that soil ET has on the coefficient, it was assumed that analysis of it would not be enlightening. Discussions of the rooting depth in the CROPWAT manual (Allen et al., 1998) suggest that it is reliant on the genetic characteristics of the crop itself, with some consideration of the restrictions soil structure may have on penetration depth. Typical rooting depths for maize and soybeans, range from 1.0 - $1.7 \mathrm{~m}$ and 0.6 - $1.3 \mathrm{~m}$, respectively. Table B.1 provides insight into the relationship between soil types and their potentially restrictive nature of root growth (Foxx et al., 1984).

Table B. 1 Maximum rooting depths for soil types found in the St. Joseph watershed (Foxx et al., 1984)

\begin{tabular}{|c|c|c|c|}
\hline Soil Type & $\begin{array}{c}\text { Maximum Rooting Depth } \\
(\mathbf{m})\end{array}$ & Drainage Class & \% in Watershed \\
\hline Clay & 2.74 & $\mathrm{D}$ & 1.38 \\
\hline Loam & 3.66 & $\mathrm{C}$ & 20.96 \\
\hline Sand & 4.57 & $\mathrm{~A}$ & 46.74 \\
\hline Silt & $>4.57$ & $\mathrm{~B}$ & 30.92 \\
\hline
\end{tabular}

Starting with maize, the initial rooting depth was left at $0.3 \mathrm{~m}$, with the maximum rooting depth adjusted to reflect the values found in Table B.1. The results for $E T_{c}$ total remained constant, suggesting that despite the attempt to accommodate various soil structures into CROPWAT, the CWR results do not differ with changes to the maximum rooting depths (Table B.). The characteristics of soybeans were not modified due to the lack of change seen in maize.

Table B. 2 Results from the CWR after adjustments were made to the maximum rooting depth.

\begin{tabular}{|c|c|c|c|}
\hline Soil Type & $\begin{array}{c}\text { Initial Rooting } \\
\text { Depth }(\mathrm{m})\end{array}$ & $\begin{array}{l}\text { Maximum Rooting } \\
\text { Depth }(\mathrm{m})\end{array}$ & $\mathrm{ET}_{\mathrm{c}}\left(\mathrm{mm} \mathrm{gs} \mathrm{s}^{-1}\right)$ \\
\hline Default & \multirow{5}{*}{0.3} & 1.00 & \multirow{5}{*}{565.5} \\
\hline Clay & & 2.74 & \\
\hline Loam & & 3.66 & \\
\hline Sand & & 4.57 & \\
\hline Silt & & 5.49 & \\
\hline
\end{tabular}

The next parameter to adjust is the critical depletion fraction, $p$. From the CROPWAT manual (Allen et al., 1998), it is noted that for soil dominated by clay, the value of $p$ should be reduced by $5-10 \%$ of the value listed and increased by $5-10 \%$ for sandy soils. As shown in Table B.3, adjustments made to $p$ yield no change in $E T_{c}$. 
Table B. 3 Results from the CWR after adjustments were made to the critical depletion fraction.

\begin{tabular}{|c|c|c|c|c|}
\hline Soil Type & $\begin{array}{c}\text { Critical Depletion } \\
\text { Fraction }\end{array}$ & Adjustment \% & Adjusted $p$ & $\mathrm{ET}_{\mathrm{C}}\left(\mathrm{mm} \mathrm{gs}^{-1}\right)$ \\
\hline Clay & \multirow{4}{*}{0.55} & $-10 \%$ & 0.495 & \multirow{4}{*}{565.5} \\
\hline Loam & & $+5 \%$ & 0.5775 & \\
\hline Sand & & $+10 \%$ & 0.605 & \\
\hline Silt & & $-5 \%$ & 0.5225 & \\
\hline
\end{tabular}

Based on studies conducted in the early 2000s (Kipkorir et al., 2002; Dagdelen et al., 2005; Oktem, 2008; Dehghanisanij et al., 2009), the yield response factor for maize ranges from 0.76 to 1.46, while the CROPWAT manual reports that this value is 1.25 . Making these changes to $K_{y}$ reflected no change in the $E T_{c}$ (Table B.4).

Table B. 4 Results from CWR after adjustments were made to the yield response factor.

\begin{tabular}{|c|c|}
\hline Yield Response Factor & $\mathbf{E T}_{\mathbf{C}}\left(\mathbf{m m ~ g s}^{\mathbf{1}}\right)$ \\
\hline 1.25 & 565.5 \\
\hline 0.76 & 565.5 \\
\hline 1.46 & 565.5 \\
\hline
\end{tabular}

The next trial used to investigate the effect that soil type has on the ET rates as calculated in the CWR module was to change the "dry" crop option to "rice" crop. This is because, although the requirements for "rice" using the CWR module are the same for those of "dry" crops, the soil module must be applied for rice. To simulate maize, values for $K_{c, d r y}=K_{c, w e t}=K_{c \text {.maize }}$; days of land prep were listed as one day total and zero days of puddling; growth stages, rooting depth, critical depletion fractions, yield response factor and crop height were kept the same as those listed in Table 9; the puddling depth could not be zero so was instead inputted as " $0.01 \mathrm{~m}$ ". As shown in Table 18 , the results verify the previous observations that the CWR module does not account for different soil characteristics. The modified rice results were slightly larger than that which results from the default maize file -- $565.6 \mathrm{~mm} \mathrm{gs}^{-1}$ versus $565.5 \mathrm{~mm} \mathrm{gs}^{-1}$-- this difference is not statistically significant and cannot be used to make any reasonable conclusions (Table B.5).

Table B. 5 Results from CWR after adjustments were made to the "rice" crop file to reflect the characteristics typically associated with "maize".

\begin{tabular}{|c|c|c|}
\hline Crop Characteristic Input & Soil Type & ET $\left._{\mathbf{~}} \mathbf{~ m m ~}_{\mathbf{~ g s}} \mathbf{- 1}\right)$ \\
\hline Maize, FAO Default & All Soil Types & 565.5 \\
\hline \multirow{3}{*}{ Maize, Modified Rice } & Light & 565.6 \\
\cline { 2 - 3 } & Medium & 565.6 \\
\cline { 2 - 3 } & Heavy & 565.6 \\
\hline
\end{tabular}

The final attempt to include soil types into the CWR method was to use daily time steps rather than monthly time steps. The result was disappointing since there was no change in the $\mathrm{ET}_{\mathrm{c}}$ as shown in Table B.6. Because of this, the CWR can be considered limited in terms of a water footprint analysis, since the green water footprint, as stated above, requires that soil characteristics be considered. Simulations were carried out with the CWR to obtain the water footprints regardless of the issues it has and can be found in the supplementary information (Figures S.1 and S.2). 
Table B. 6 Results from the CWR after the time-step was adjusted to daily, rather than monthly as in previous simulations.

\begin{tabular}{|c|c|}
\hline Time-Step & ETc $\left(\mathbf{m m ~ g s}^{-1}\right)$ \\
\hline Monthly & 565.5 \\
\hline Daily & 565.5 \\
\hline
\end{tabular}

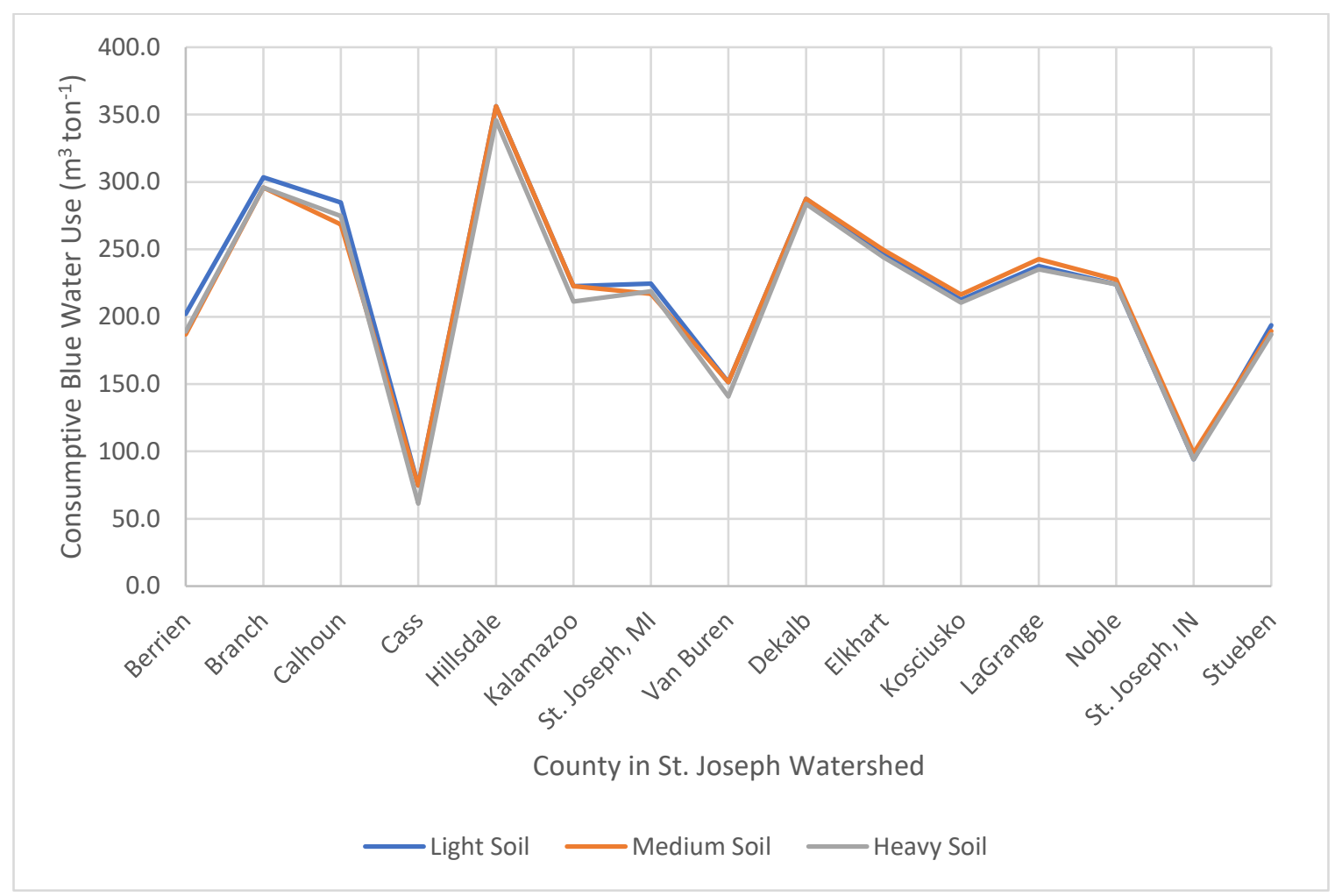

Figure S. 1 CWR Output for consumptive blue water footprint for maize grown in each county in the St. Joseph watershed in 2016 


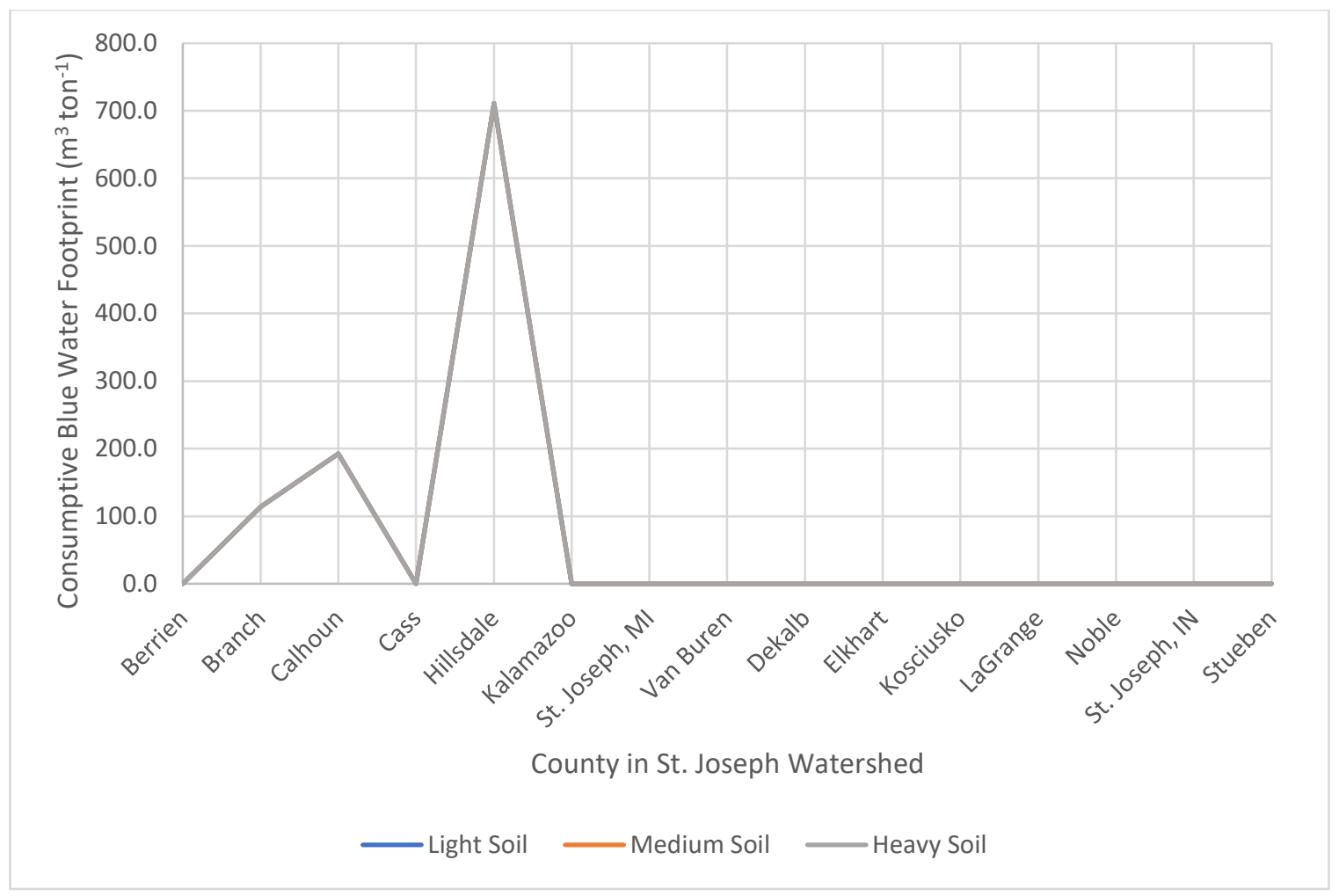

Figure S. 2 CWR Output for consumptive blue water footprint for soybeans grown in each county in the St. Joseph watershed in 2016 